This is a Working Copy Version (for personal use) of the paper, which has been published in ENERGY. Citation:

N. Pacheco, F.P. Brito, R. Vieira, J. Martins, L.M. Goncalves, Compact Automotive Thermoelectric Generator with Embedded

Heat Pipes for Thermal Control, Energy, 197 (2020) 117154; https://doi.org/10.1016/j.energy.2020.117154 , Official copy

available here: https://www.sciencedirect.com/science/article/pii/S0360544220302619?via\%3Dihub

\title{
Compact Automotive Thermoelectric Generator with Embedded Heat Pipes for Thermal Control
}

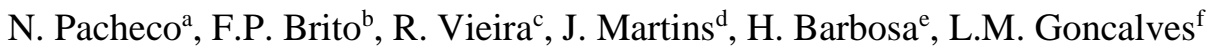 \\ a, b, c, d, e MEtRICs, Department of Mechanical Engineering, University of Minho, Guimarães, Portugal \\ ${ }^{\mathrm{f}}$ CMEMS, Department of Industrial Electronics, University of Minho, Guimarães, Portugal \\ * Corresponding authors: ${ }^{a}$ b7371@dem.uminho.pt, bfrancisco@dem.uminho.pt, cb8024@ dem.uminho.pt, \\ djmartins@dem.uminho.pt, ${ }^{\text {a }}$ 79071@alunos.uminho.pt, flgoncalves@dei.uminho.pt
}

\section{KEYWORDS}

Thermoelectric generator; variable thermal load; waste heat recovery; thermal control; heat pipes; variable conductance heat pipes

\begin{abstract}
Currently, the automotive industry faces challenges to implement solutions that provide reductions in energy consumption, pollutants and greenhouse-gas (GHG) emissions. Exhaust heat recovery employing Thermoelectric generators (TEGs) enables the direct conversion of heat into electric energy without moving parts and little to no maintenance. On-board electrical production is especially useful given the growing electrification trend of road vehicles. The present work assesses the performance of a novel temperature-controlled thermoelectric generator (TCTG) concept in a light duty vehicle and its impact on fuel economy and GHG emissions under realistic driving conditions. The novel exhaust heat exchanger (HE) concept consists of corrugated pipes embedded in a cast aluminium matrix along with variable conductance heat pipes (VCHPs) acting as spreaders of excess heat along the longitudinal direction. This concept seems to have a quite good potential for highly variable thermal load applications, as it is able to avoid overheating by spreading heat instead of wasting it through by-pass systems. Furthermore, when compared to previous concepts by the group, it does not need gravity assistance and has a form factor similar to conventional generators. It also appears to be capable of delivering a breakthrough electric output for TEG systems in such light vehicles, with as much as $572 \mathrm{~W}$ and $1538 \mathrm{~W}$ of average and maximum electric powers during a driving cycle, respectively, and showing a quite promising reduction of $5.4 \%$ in fuel consumption and $\mathrm{CO}_{2}$ emissions.
\end{abstract}

\section{INTRODUCTION}

\section{Reason for thermal control}

The automotive industry research and development for the next years will have to adapt to new goals for the overall reduction in energy consumption as well as lower pollutant and greenhouse-gas (GHG) emissions [1]. In terms of fuel consumption, the 2021 European Union target is set to $4.1 \mathrm{~L} / 100 \mathrm{~km}$ in petrol engines and $3.6 \mathrm{~L} / 100 \mathrm{~km}$ in diesel engines, with a target for the fleet average of $95 \mathrm{~g} / \mathrm{km}$ of $\mathrm{CO}_{2}$ emissions [2]. These targets will be even stricter for 2030.

A significant increase in vehicle efficiency can be achieved both in the internal combustion engine (ICE) improvement and on other peripheral systems. The main goal in this project is the reduction of energy consumption by the engine, by replacing part of the electric power produced by the alternator. On-board electricity production is especially useful given the growing electrical demands for road vehicles [3]. The concept explored by the research group aims at the recovery of the exhaust heat and its direct conversion into electric energy through thermoelectric generators (TEGs). This system is devoid of moving parts and has little to no maintenance needs. Several TEG prototypes have been developed and tested by major OEMs [4]-[7] but until now no system has been released to the market, as the results obtained so far have not been sufficiently attractive.

Presently, commercial TEGs present some limitations such as low efficiency and high cost [8]. They are also temperature limited. Recently developed materials such as magnesium silicides have increased slightly their maximum allowable temperature $\left(\sim 400^{\circ} \mathrm{C}\right)$, but the most available modules (bismuth telluride) just reach around $250^{\circ} \mathrm{C}$ [8]. On one hand, it is desirable that the heat absorbed from the exhaust be maximized, as the availability of heat under urban driving is not high. This means to increase the heat exchanger effectiveness (defined as the ratio between the absorbed heat and the maximum absorbable heat) as much as possible. Also, TEGs need to work close to their temperature limit and with a temperature as uniform as possible to be efficient [9]. On the other hand, if that temperature is exceeded, seizure ensues.

If the exhaust heat exchanger displays a high effectiveness, then a high fraction of the exhaust heat will be absorbed but also the risk of overheating will rise. In order to avoid this occurrence, by-pass valves are commonly used by existing systems to divert waste exhaust gases during high power events [10]. However, this results in wasting a significant amount of energy that could otherwise be harvested.

To overcome the aforementioned problems, several innovative approaches have been explored by the authors to control the TEG temperature without losing recovery potential. With that intention, TEG systems featuring temperature control 
using variable conductance (VC) thermosiphons (TS) were proposed [11]-[15]. Basically, these systems would operate as follows:

- the exhaust heat would be absorbed by an evaporator, in which vapour would be generated;

- This vapour would be responsible for carrying all the thermal energy to the thermoelectric modules, which would be attached to the heat sink portion of the thermosiphon, also called the condenser;

- The evaporator and the condenser would be connected through a vapour line, with the condensates returning from the condenser to the evaporator by gravity. This system is described as possessing a variable conductance because the vapour will only fill a fraction of the condenser, with the rest of the space being filled by a noncondensable gas.

- The vapour would fill a higher or a lower portion of the condenser depending on the higher or lower thermal power available at the exhaust;

- The thermoelectric modules would be attached to the condenser part of the system and the heat would be supplied to the modules through the condensation of this vapour;

- Only the part of the condenser that would be occupied by vapour would be active, the remaining part would be occupied by the non-condensable gas and would be inactive.

- The presence of the non-condensable gas allows two different features of the system: one is the variable conductance (the variable heat transfer area). The other feature is the ability to control the operating temperature range (e.g. the phase change temperature) of the system.

- The working temperature of the system would correspond to the boiling temperature of the phase change fluid. This temperature is only a function of the inner pressure. Therefore, the inner pressure would be regulated through the pre-charge of the non-condensable gas within the system. This pressure would vary within controlled values depending on the volume of the system.

The authors performed the modelling of aforementioned system, first under fixed pressure and including full experimental validation [11], [12], [14]. Subsequently, the model was applied to realistic driving cycles with fixed pressure/temperature [13] and finally allowing also for realistic pressure variation during the driving cycle [15]. In this latter work several volumes of the system were tested allowing for lower or higher ranges of pressure variation during the driving cycle. It was concluded that actually it may be advantageous to have lower volumes a therefore allow for some pressure fluctuation between start-up and full power. This way, it was possible to achieve an optimized operation of the system as it was possible to adjust the temperature of the hot face of the module close to the ideal level mostly independently of thermal input. The variation of this thermal input would mainly affect the active number of modules and not so much the hot face temperature. This means that it was possible to achieve an average efficiency of the system during a driving cycle that was very close to the maximum efficiency of the TEG modules, yielding unparalleled performance for light duty vehicles (close to $300 \mathrm{~W}$ average power during the WLTC 3 driving cycle and $600 \mathrm{~W}$ under a custom highway cycle, with maximum powers overcoming $1 \mathrm{~kW}$ ).

One of the disadvantages of the thermosiphon-based concepts is that they would require gravity and some vertical space to operate, which is not easily implemented on a light duty vehicle. Another disadvantage is that the exhaust heat could not be totally absorbed by the system, as the exhaust could only be cooled down to the operating temperature of the evaporator (around $250^{\circ} \mathrm{C}$ in the case evaluated). If higher temperature modules would be used, this problem would be even more critical. There is an alternative way of using phase change phenomena for the control of the TEG hot face temperature. An alternative to performing all the heat transfer through phase change, would be to perform the heat transfer through convection and conduction and then complement it with phase change.

\section{Thermal control through heat spreading}

Thus, a new compact system based on variable conductance heat pipes (VCHPs) which does not need gravity to operate has been explored and submitted for patenting [16], [17]. In this concept the phase change process is no longer used to transfer all the heat to the TEG modules but will only be used to spread the excess heat from hotter to cooler regions of the generator. To do this, the concept of excess heat spreading outlined in Figure 1a was used. It uses VCHPs embedded in the exhaust heat exchanger between the exhaust flow and the TEG modules to transfer longitudinally the excess heat by phase change within the heat pipes. Basically, when the engine is working under high power, such as when driving uphill on a motorway, the heat absorbed at the first rows of modules might be excessive (see continuous line in Figure 1a representing the module hot face temperature). The intention is to absorb the excess heat produced at the upstream region of the HE and release it to the cooler regions located downstream, as represented schematically by the dashed line of Figure 1a. This would prevent overheating, allow a more uniform temperature distribution and avoid wasting exhaust energy as would be the case of bypassing the heat. The way of achieving this would again be through phase change at a specific boiling temperature.

This concept can actually be implemented by embedding VCHPs in the exhaust heat exchanger between the heat source and the TE modules, as depicted in the lower portion of Figure 1a. The VCHPs would have the function of absorbing excess heat at hotter regions of the HE (by vaporization), transporting this heat in the longitudinal direction and releasing it at the cooler regions (by condensation) located downstream as illustrated in Figure 1a,b. In order to explain how this is achieved it is important to understand how HPs, and particularly VCHPs work. 

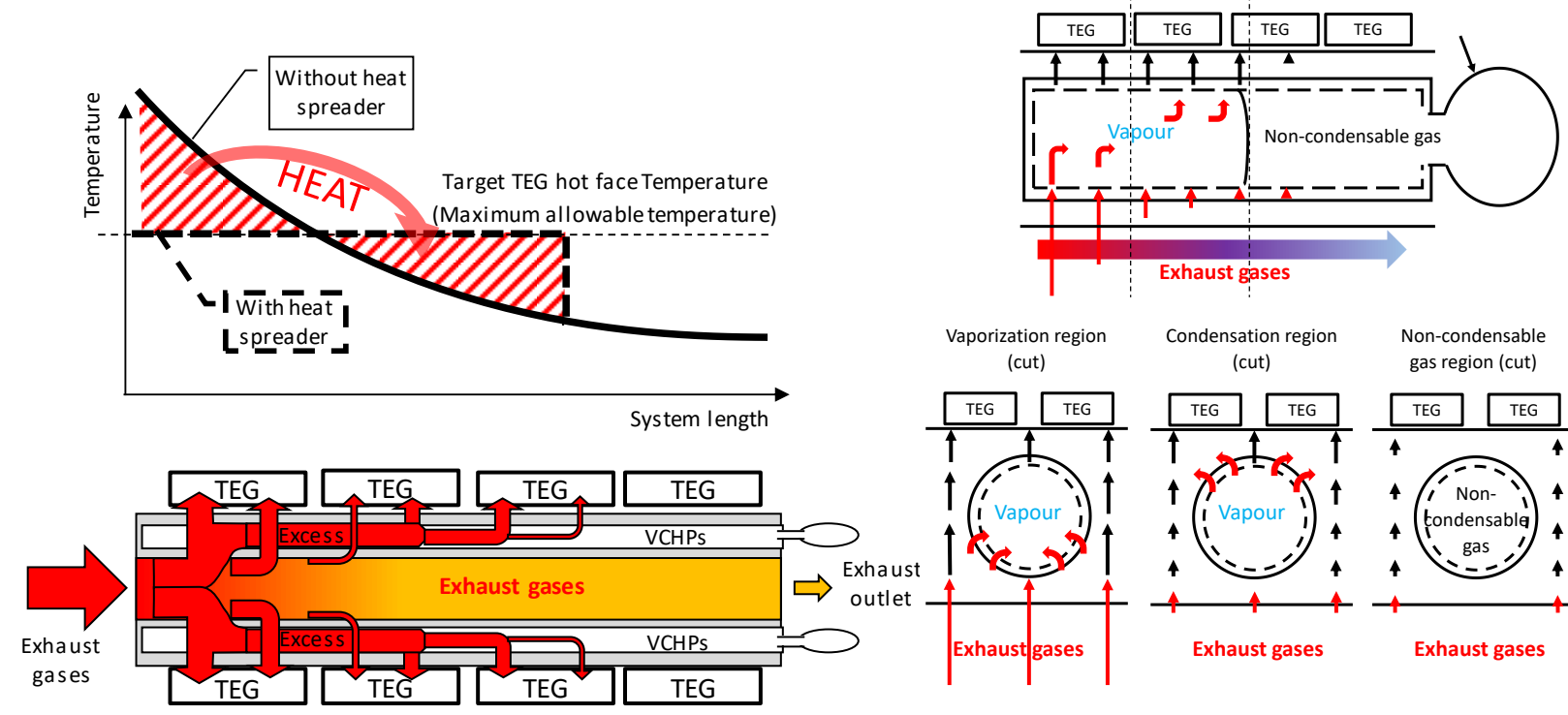

a)

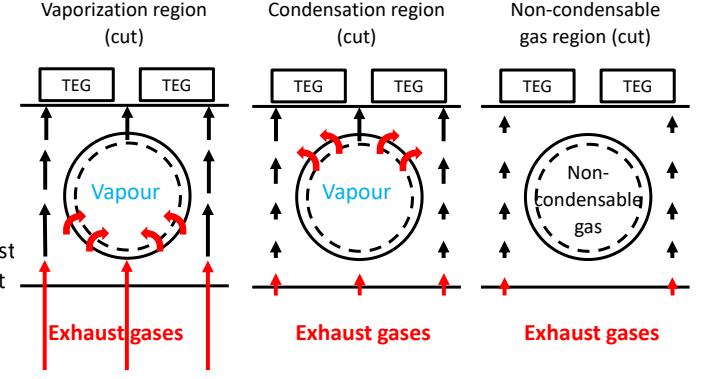

b)

Figure 1 - Schematic representation of the excess heat (a) spreading enabled by the use of VCHPs and (b) being absorbed by the VCHP at the hotter regions and released to the cooler regions.

\section{Variable conductance heat pipe operation}

Heat Pipes (HPs) and ThermoSyphons (TSs) are devices constituted by a sealed tube with a small amount of phase-change fluid inside it, allowing a large amount of heat transfer from a heat source to a heat sink through phase change [18]. The fluid absorbs the heat at the heat source by vaporization (portion of tube that works as evaporator) and releases it at the heat sink by condensation (portion of tube that works as condenser, where heat will be released) [19]. Since phase change is involved, the thermal resistance between the heat source and the heat sink is very low.

In TSs the return of the condensed fluid from the heat sink to the heat source is done by gravity (the condensing region is located above the vaporization region). In HPs the return of the condensed liquid is done through capillary pumping [18], [19]. This effect is obtained using a layer of porous sintered metal powder, metallic meshes, small channels or a combination thereof attached to the inner walls of the HP [20], [21]. This feature allows the HP to operate horizontally without the need for gravity assistance. This makes its usage very flexible.

VCHPs are basically HPs which also have a non-condensable gas in addition to the phase change fluid. This is schematically represented in Figure 1b. Unlike HPs, which are always at saturation conditions, VCHPs will only start to transfer heat once the saturation conditions are met, at a very specific temperature. This temperature may be adjusted by the preload pressure of the non-condensable gas, which determines the temperature at which the phase change occurs. The higher the volume of the VCHP is, the more stable this temperature will be. Additionally, VCHPs will display two different regions under operation, as depicted in Figure 1b: one active region where the generated vapour is located and one inactive region occupied by the non-condensable gas, which is close to adiabatic. The phase-change fluid and noncondensable gas will occupy different regions and will not mix significantly [20]. The amount of vapour produced will occupy a smaller or a greater portion of the VCHP, according to the available power from the heat source. The farther the vapour region expands, the larger the heat transfer area will be because the non-condensable gas region will shrink, displaced by the vapour [20]. The addition of an expansion volume will make the process occur at a fairly constant pressure irrespective of the exhaust temperature and flow rate [13]. The temperature stability and variable active heat transfer area provided by vapour/non-condensable gas stratification has been well explained and documented experimentally by the authors with TS-based systems in the past [12] and by literature [20].

\section{Heat exchanger concept}

A global view of the horizontal concept of the temperature-controlled thermoelectric generator (TCTG) incorporating VCHPs is represented in Figure 2a. The cut in Figure $2 b$ allows to see the inner structure of the concept. Basically, it consists of: (i) a cast aluminium block (light grey) in which corrugated tubes and VCHPs are embedded; (ii) finned water cooling plates (blue); (iii) TEG modules (red) between the aluminium block and the coolers. The cast aluminium matrix allows to seamlessly integrate the stainless steel corrugated tubes, which are identical to those used in Exhaust Gas Recirculation (EGR) coolers, and the VCHPs, which can be made of various materials, notably copper. 
The heat of the exhaust gases flowing inside the corrugated tubes is absorbed by the heat exchanger. This heat flows from the corrugated tube walls to the TEG modules by conduction across the aluminium. However, the VCHPs are located between the corrugated pipes and the TEG modules so that they will interfere with the heat flow in the event of excessive heat.

The way VCHPs act was already outlined in Figure 1 and is as follows: their preload pressure is set so that they will only start vaporizing and absorbing heat once their vicinity reaches the temperature limit of the modules. As long as the thermal level of the HE is lower than this temperature, all the heat absorbed by the HE will reach the modules purely by conduction across the heat exchanger and the VCHP will not be active (no vaporisation and no condensation occurs).

Once the hotter regions of the HE exceed the limit temperature, the VCHPs will start absorbing this excess heat by vaporization, thus preventing further rise of the temperature above the limit temperature. The excess heat absorbed by the VCHPs will generate vapour and this vapour will start filling a portion of the VCHPs volume, expanding downstream towards the cooler regions of the HE, as seen in Figure 1b. Thus, the heat spreading occurs in the longitudinal direction by phase change and mass transfer along the VCHPs. Some of the vapour accumulated inside the VCHPs will eventually reach the cooler regions located downstream, condensing and heating these regions. This way, all the vapour domain will be around the saturation temperature (dashed line of Figure 1a). The heat will flow, by conduction, from the corrugated tubes through the metal parts and TEGs to the cooling plates. When the boiling point is met at the VCHPs, they will start spreading the excess heat in the longitudinal direction, controlling the TEG hot face temperature. Hence, varying thermal loads result in a varying number of active TEG modules rather than overheating (see Figure 1a).

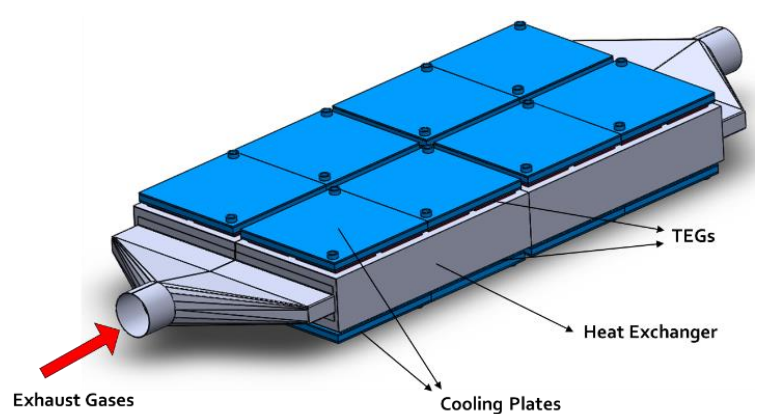

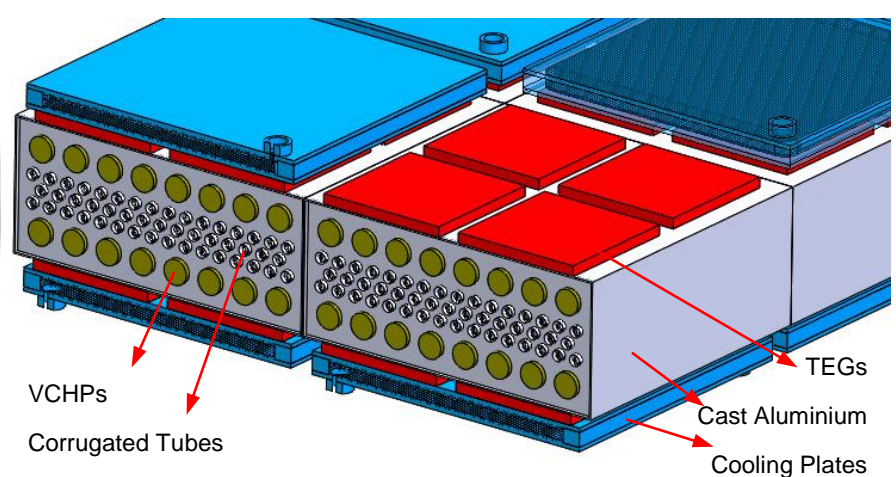

(a)

Figure 2 - (a) global and (b) cut overview of temperature-controlled thermoelectric generator concept based on corrugated tubes and VCHPs.

Regarding the HE design, two different compact heat exchanger types (exhaust gas side) have been studied by the group in conjunction with VCHPs to spread the excess heat: stainless steel corrugated pipes and offset fins. However, the offset fins based solution is much more prone to fouling [22] which would reduce the HE effectiveness, therefore, corrugated tubes seem preferable. These corrugated tubes are widely used in exhaust heat exchangers, namely in Exhaust Gas Recirculation (EGR) coolers, so they are optimized for exhaust environment, are not as susceptible to fouling and typically display a low pressure drop under operation. Moreover, they are commercially available. A low thermal resistance solution is to embed both corrugated pipes and VCHPs in a common cast aluminium substrate for seamless physical and thermal continuity between the dissimilar materials. This was the chosen solution, as already depicted in Figure 2, with three rows of corrugated tubes (for the exhaust gases) at the centre and one row of VCHPs at each side (top and bottom), next to the TE modules.

A low thermal resistance integration of stainless steel corrugated tubes and copper VCHPs is a challenging proposition. However, as shown in Figure 3, some attempts to cast a downsized proof-of-concept prototype were successful and it seems a feasible process despite the iterative process given the innovative genesis of the device. Moreover, all the issues detected will be easily corrected in the upscaling of the prototype.

Ideally, the heat exchanger should be located horizontally along the exhaust line, after the catalyst and as close as possible to it so that thermal losses are minimized. 


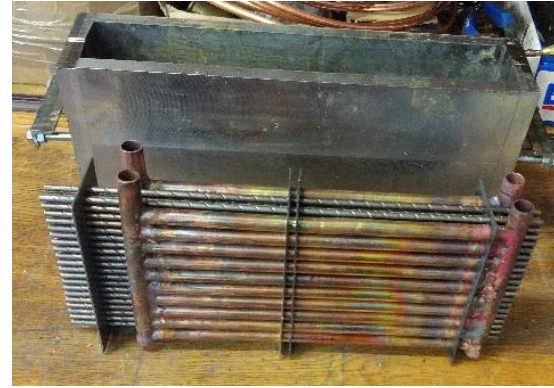

a)

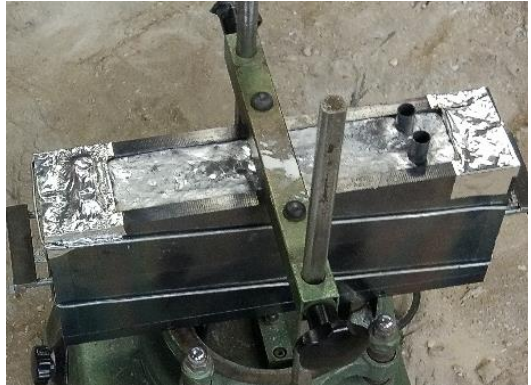

b)

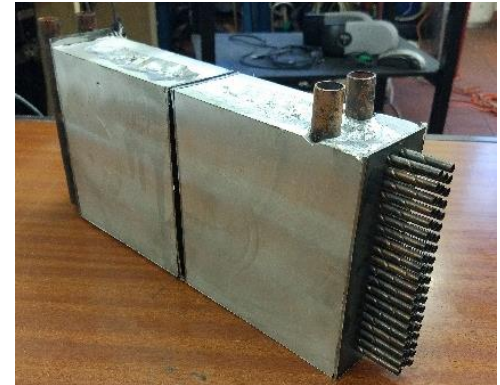

c)

Figure 3 - a) HPs and tubes arrangement before casting; b) HE inside the moulding; c) HP's and corrugated tubes embedded in cast aluminium.

\section{MODELLING - GLOBAL APPROACH}

A mathematical model was developed to predict the system behaviour and to optimize the geometry of the TCTG to be installed in a light duty vehicle. The electrical output of the TEGs, as well as their impact on fuel economy and GHG emissions, were assessed under the Worldwide Harmonized Light Vehicle Test Cycle class 3 (WLTC) and a custom highway (HW) cycle already described in previous works [13].

It is a quasi-steady state model that incorporates suitable empirical correlations for convection at the corrugated tubes and at the cooling plates (described in continuation), 1D equivalent thermal conduction resistances estimated from 2D conduction solvers and thermoelectric calculations to estimate the matched load power output of the TEGs. Since the main aim of the present work is to assess the thermal performance of the present concept, a simplified thermoelectric model was used. Average thermoelectric properties were used, with the Peltier effect being incorporated into an effective thermal conductance similarly to what has been done by other authors [23]. The physical properties (Seebeck/Peltier coefficient, thermal conductivity, electrical resistivity) were calibrated against the datasheets from the manufacturer, so the electric output of the modules correlates well with the actual modules available in the market [24].

The geometry of the simulated system is partially seen in Figure 2. The cold faces of the TEGs are cooled by densely finned cooling plates. As seen in Figure 2, each cooling plate serves $2 \times 2$ TEG modules. At each side (top/bottom) there are $4 \times 2$ cooling plates along the length/width of the generator (Figure 2).

The flow of the exhaust gases and of the coolant is arranged in counter current. Each cooling plate has an independent stream of cooling water (parallel configuration). Since the cooling flow occurs in parallel for the various cooling plates, the flow temperature is reset to the coolant inlet temperature, $\mathrm{T}_{\mathrm{ci}}$ at the entry of each plate, instead of a continuous increase of water temperature along the entire length of the HE. The cooling plate model also evaluates the pressure drop. The convective heat transfer coefficient and the pressure drop for the cooling plates were estimated using empirical correlations for developing flow in non-circular ducts [25]. A cooling circuit independent from the engine cooling circuit has been considered in order to minimize the cold side temperature. Such a configuration is compatible with many of the existing car models which incorporate low temperature liquid cooling circuits for systems such as liquid cooled turbo intercooler systems.

The entire length of the system was numerically discretized into 72 sections, with the thermal calculations in each section being performed in 1D and with the exhaust/coolant outlet temperature of one section corresponding to the inlet temperature of the subsequent section, flow-wise. In each section the heat flux goes from the HE (corrugated tubes) to the cooling plates. Heat conduction along the exhaust gases direction was not considered. Actually, in the prototype the aluminium casting will have a physical discontinuity between each row of modules, so this assumption is acceptable.

The engine conditions necessary to fulfil the driving cycle were predicted using a steady-state engine model, from which the exhaust mass flow and temperature maps were extracted for each time step of the cycle (steps of one second). This model, which has been described in detail elsewhere [26]-[28], is a one zone model, with the combustion following a Wiebe function and variable gas properties. Heat transfer follows Annand's model [29], [30], Friction follows Patton, as well as Sandoval and Heywood models [31], with the mass flow entering and leaving the cylinder being treated with a compressible flow model [32]. The validation of the model with experimental tests provided errors below $7 \%$ for the range of speeds typical of real driving cycles $(<3000 \mathrm{rpm})$ [25]. The exhaust gas temperature was obtained from the temperature at exhaust valve opening (EVO) corrected with the thermal losses occurring at the portion of the exhaust duct embedded in the cylinder head, where engine cooling is very relevant. Downstream of the engine, the exhaust flow is considered to be well insulated until the generator. While it is true that existing vehicles do not normally insulate the exhaust piping, it is something which would be desirable for exhaust heat recovery applications.

The driving cycle energy model used to compute the instantaneous engine torque and speed required to fulfil the cycle has been detailed and assessed in previous publications [13], [28], [33], [34]. It accounts for the main energy fluxes involving driving namely, aerodynamic drag, rolling resistance (including tire slip and cornering force when applicable), 
road slope forces and inertial forces under acceleration and deceleration. For each time step the exhaust temperature and flow rate are extracted from the engine map for the operating conditions obtained from the driving cycle model.

Regarding the exhaust flow within the TE generator, the properties of the exhaust gases were approximated by those of dry air, since no substantial error ensues. The properties vary mainly as a function of temperature and pressure, but pressure is expected to be close to atmospheric, therefore, its variation is not significant and only temperature will play a role. These properties are computed based on available equations for this purpose [35], [36]. Regarding convection, correlations for corrugated tubes for laminar, transitional and turbulent regimes [35], [37], [38] were adopted, with these empirical results having been validated with a full 3D CFD analysis performed to a single corrugated pipe using the realizable k- $\varepsilon$ algorithm [39]. Figure 4a represents the temperature evolution along the flow lines in the corrugated tube. Heat transfer and pressure drop were compared against model predictions (results are presented further along this document).

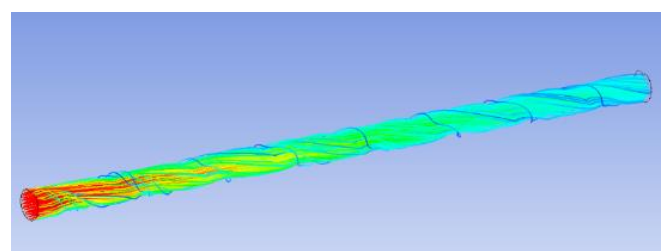

a)

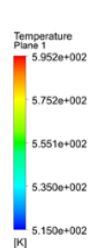

${ }_{[\mathrm{K}]} \mathrm{5.1500+002}$

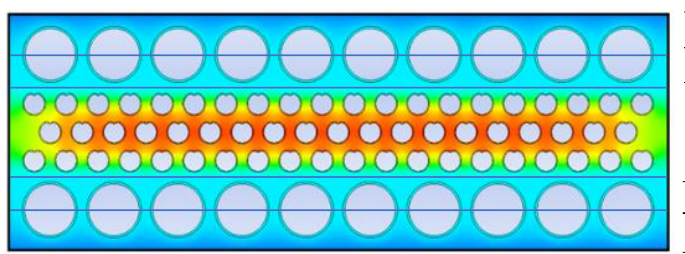

b)

Figure 4-(a) CFD simulation of a corrugated pipe; (b) 2D heat conduction simulation of the exhaust heat exchanger

The thermal power transferred from the exhaust gases to the cooling water for each one of the 72 longitudinal numerical calculation sections depends on the HP thermal resistance. This thermal resistance is different whether the HPs are active or inactive in that particular section. For the calculation of the active/inactive HP equivalent 1D thermal resistances, either an adiabatic or an isothermal HP wall was considered as a boundary condition for the 2D solver, respectively. This would allow to extract the thermal resistances of the system for the inactive and active HP regions, respectively. in Figure $4 \mathrm{~b}$ an example can be seen of the 2D heat conduction simulation of the exhaust heat exchanger to obtain the equivalent 1D thermal resistances of the different regions of the heat exchanger crossed by the heat flow. There is the central block containing the corrugated tubes embedded in the aluminium and then there is the region where the HPs are embedded which was divided into a region upstream of the HPs and another one downstream of the HPs (R1, R2, respectively).

The 1D thermal resistances were derived from the 2D simulations as follows: heat inlet and outlet surfaces were defined with suitable boundary conditions (convection or fixed temperature), then the heat transfer rate was calculated in $2 \mathrm{D}$ with a commercial package. The resulting 1D thermal resistances are the ratio between the temperature difference that was imposed and the heat transfer rate, $\dot{Q}$, that resulted from that temperature difference $(R=\Delta T / \dot{Q})$.

The thermal resistance depends on geometry and on thermal conductivity, so it may be expressed in terms of the Shape Factor, $S$, and the thermal conductivity, $k(R=1 / k S)$ [40]. This way, once $S$ is determined for a given set of temperature conditions, it may be used for the heat transfer calculations under other conditions. For obtaining the thermal resistance of the corrugated tube block (central part of Figure 4b), a fluid temperature along with a convection boundary condition at the inner surface of the corrugated tubes was imposed, while a constant temperature of the outlet surface was imposed. For the regions upstream and downstream of the HPs a fixed temperature difference between the heat inlet and outlet surfaces was set, with the surface of the HP being either adiabatic or isothermal. Once these thermal resistances were obtained, they were used to calculate the heat transfer under each one of the driving cycle time steps.

Several corrugated tube configurations were simulated in order to derive the thermal resistances and the optimal geometry in terms of tube spacing and number of rows.

The way that the thermal spreading performed by VCHPs is modelled is by performing thermal and mass balances to each calculation section in the longitudinal direction. In this scope, the thermal power accumulation (region of vaporization) or depletion (region of condensation) inside the HPs is calculated at each numerical section, as outlined in Figure 1. Starting at the first section, it is initially assumed that the HPs are not active and the temperature field is calculated at each node of the 1D thermal model with an adiabatic HP. Then, if the calculated thermal level at the HP node is found to exceed the HP boiling temperature, it means that the HP in reality is active and we are in the vaporization region of the HP. Under these conditions, the thermal calculations are repeated, but now considering the HP as isothermal (at boiling temperature). In this case, two separate 1D thermal calculations are done, one upstream and the other one downstream of the HPs, providing two corresponding thermal powers (into and out of the HPs). As in a thermal balance, the difference between the two corresponds to the excess thermal power absorbed (or released if the value is negative) by the HPs through vaporization in that particular section. The excess power absorbed or released by the HPs at a given calculation section represents the vapour that is being generated or condensed at that section. The vapour that has been generated in a given section is added to the total accumulated vapour power inside the HPs. Conversely, if there is heat deficit in a section, the accumulated vapour power will be depleted in that section and in the subsequent sections until it has been entirely depleted. This is illustrated for a specific case (instant 219s of the HW driving cycle) in Figure $\mathbf{5}$. 


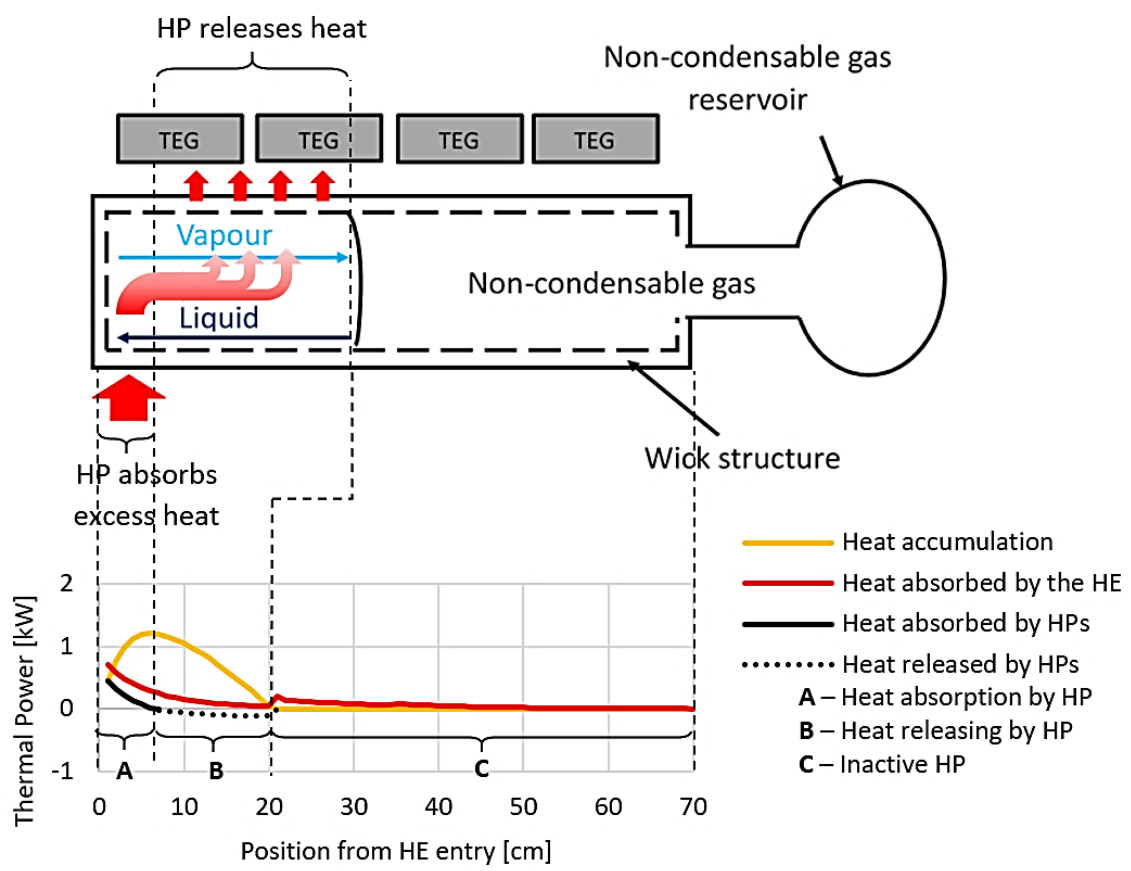

Figure 5 - Schematic representation of the excess heat spreading by HPs, taking as example the conditions represented in the Figure 8e.

The heat absorbed by the heat exchanger (in red) is excessive from the heat exchanger entry to around $7 \mathrm{~cm}$ into the HE. This means that if no HPs would be present, the maximum allowable temperature of the TE modules would be overcome in this region. Therefore, a part of this heat is absorbed by the HPs (black line of Figure 5). The accumulation of this heat is represented by the light orange line. Beyond $7 \mathrm{~cm}$ excess heat is no longer present, that is, if no HPs would be present, the temperature of the modules would be less than optimal (recall Figure 1). Under these conditions the vapour that was accumulated in the preceding sections starts being condensed, or in other words, the accumulated heat starts being released by the HPs to the heat exchanger (dotted black line) until no vapour is left beyond $20 \mathrm{~cm}$ of length. These downstream sections, in which all accumulated vapour power has been depleted, correspond to the inactive part of the HPs (the part filled with non-condensable gas). In this region the HPs are considered to be adiabatic (they do not absorb nor release heat) and all the heat transfer occurs exclusively through conduction across the solid metal media. The results section illustrates three different cases with low thermal power input (HPs are inactive), medium thermal power input (HPs are partially active) and high thermal power input (HPs are fully active).

The heat absorbed by the HE at each section is used to compute the outlet exhaust gas temperature of that particular section. This outlet temperature will then correspond to the inlet temperature of the next section.

\section{THERMAL DESIGN, OPTIMIZATION AND VALIDATION}

In order to identify the layout that minimizes the equivalent $1 \mathrm{D}$ thermal resistance, $2 \mathrm{D}$ heat conduction simulations were performed for several configurations of the HE: different numbers of corrugated tubes, HPs, and spacing between them. Figure $4 \mathrm{~b}$ already illustrates one of the simulations performed to calculate these thermal resistances, with horizontal lines dividing the calculation domains. One conduction thermal resistance was obtained for the corrugated pipes region $\left(R_{c d}\right.$ corrugated pipes). Other two split thermal resistances were calculated across the heat pipe region $\left(R_{c d ~ H P 1}\right.$ and $R_{c d ~ H P 2}$, see Figure 4b) which represent the equivalent 1D thermal resistances upstream and downstream of the HPs, with the heat absorption/release being considered to occur, for calculations purpose, in the line drawn between $R_{c d} H_{P 1}$ and $R_{c d} H P 2$. Regarding the geometric optimization, the spacing between corrugated tubes was limited by the casting process to a minimum of $2 \mathrm{~mm}$. The pipe spacing affects the total number of corrugated tubes in the exhaust gases, the heat transfer area, the exhaust velocity, and by consequence, the convective heat transfer coefficient and also the pressure drop which may affect negatively the engine power output due the increase of the exhaust-flow resistance [3], [41]. Figure 6 shows an example of the calculations in which the exhaust heat exchanger, including the block with embedded corrugated tubes 
and heat pipes, the TEG modules and the densely finned cooling plates were analysed for three horizontal rows of corrugated tubes. The same geometry but with only two rows of tubes was also simulated but it was discarded due to much higher thermal resistance and pressure drop.

Figure 7a outlines, for each corrugated tube spacing, the resulting total thermal resistance between the gases and the TEG modules for situations of inactive (adiabatic) and active (isothermal) HPs, as well as the average pressure drop for each driving cycle. It may be seen that the thermal resistance and the pressure drop are minimized when the tube spacing is minimum. Upon inspection of the specific components of the thermal resistance, it was found that the drop in convection resistance is responsible for this trend (tighter spacing means more tubes, more convective heat transfer area), with the conductive resistance variation with tube spacing being negligible.

It can be further seen in Figure 7a that the total thermal resistance of the system is lower when the HPs are operating (in isothermal rather than in adiabatic status) and the thermal resistance is higher for the lighter duty WLTC driving cycle than for the higher duty HW cycle. This is because the average exhaust power is lower for the WLTC and thus the average flow speed and convective heat transfer are also lower.

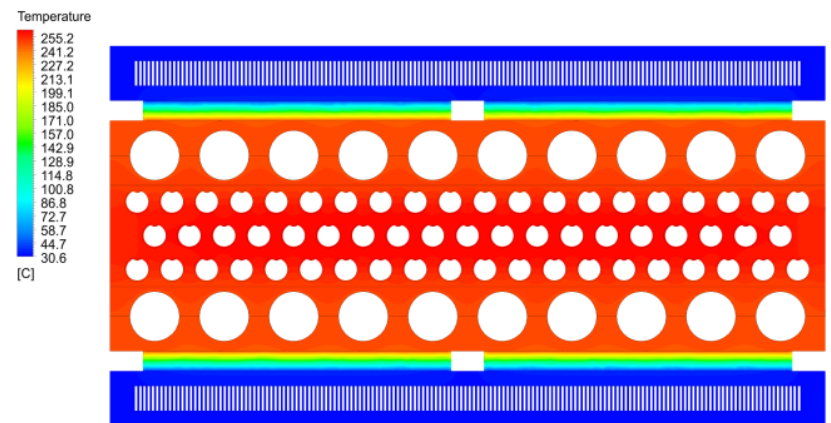

Figure 6-2D heat conduction simulation of the TCTG with three horizontal rows of corrugated tubes.

Figure 7b) shows the influence of tube spacing, driving cycle (WLTC / HW) and TEG type (GM127 or GM49) on the resulting electric output and $\mathrm{HE}$ weight. It may be seen that having a closer spacing (more tubes) will reduce the amount of cast aluminium, reducing weight, while the electric power output is almost constant. From these two Figures it seems obvious that the closest spacing possible is desirable for reasons of lower thermal resistance, pressure drop and weight. Thus, the minimum possible spacing of $2 \mathrm{~mm}$ was chosen and used thoughout this work.. It should be noted that the weight penalty was not considered in the present work, but other studies have quantified it at around 0.2 to $0.4 \%$ fuel penalty [42].

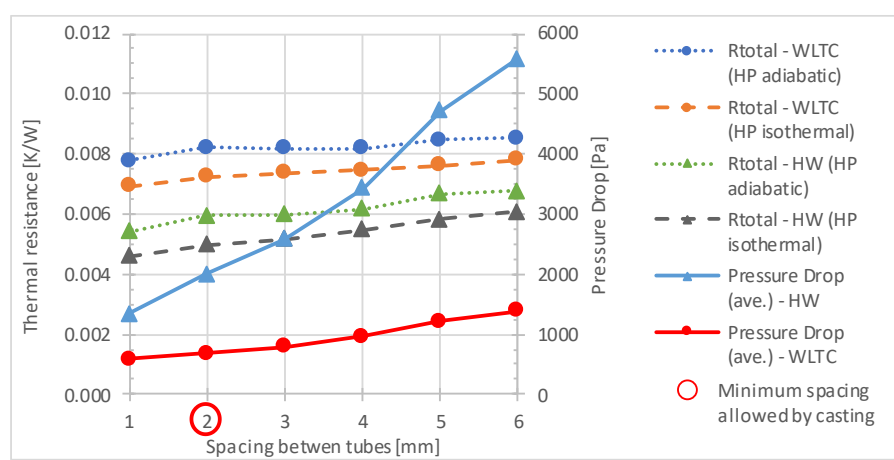

a)

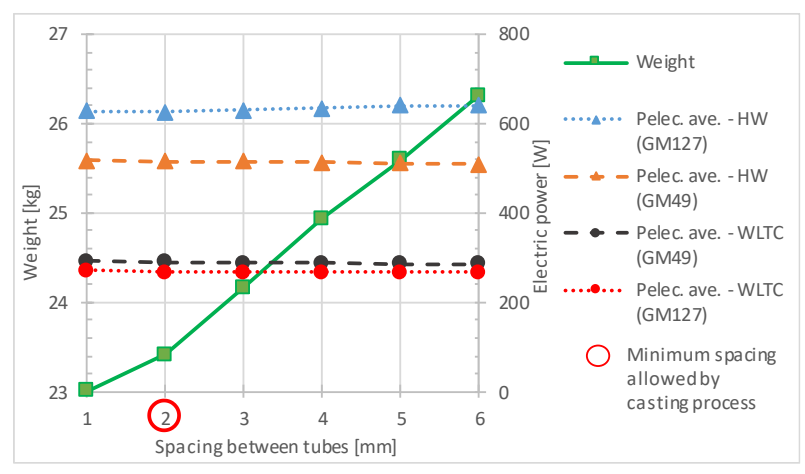

b)

Figure 7 - (a) conduction/convection thermal resistances and pressure drop; (b) Electric power and resulting HE weight.

A comparison of the convection parameters obtained from the empirical correlations and from the CFD solver was made. Table 1 shows the results obtained for two operating points located in the laminar and turbulent regimes. The differences found for the Nusselt number $(\mathrm{Nu})$, heat transfer coefficient $(\mathrm{h})$ and pressure drop $(\Delta \mathrm{p})$ were generally within the error typical of empirical correlations. The biggest error was found in the pressure drop under laminar conditions, with the model over-predicting the CFD results. In design terms, this is safer than the opposite (under-predicting). Nevertheless, the CFD results may still fail to fully represent all the phenomena present and it is worth noting that the empirical correlations have been extracted from extensive experimental testing, so their reliability is fairly solid. Therefore, it seems reasonable to assume that the convection calculations have been sufficiently validated for this geometry. 
Table 1 - Comparative results for numerical and CFD simulations.

\begin{tabular}{|c|c|c|c|c|c|c|c|}
\hline \multirow{2}{*}{ Variable } & \multirow{2}{*}{ Units } & \multicolumn{2}{|c|}{ Laminar regime $(\mathrm{Re}=936)$} & \multicolumn{3}{c|}{ Turbulent regime $(\mathrm{Re}=4581)$} \\
\cline { 3 - 8 } & & Model & CFD & Dif. & Model & CFD & Dif. \\
\hline $\mathrm{Nu}$ & - & 13.9 & 11.8 & $15 \%$ & 29.1 & 33.3 & $-15 \%$ \\
\hline $\mathrm{h}$ & {$\left[\mathrm{W} / \mathrm{m}^{2} . \mathrm{K}\right]$} & 166 & 138 & $17 \%$ & 430 & 514 & $-20 \%$ \\
\hline$\Delta \mathrm{p}$ & {$[\mathrm{Pa}]$} & 267 & 175 & $35 \%$ & 5423 & 6420 & $-18 \%$ \\
\hline
\end{tabular}

Although conduction calculations are 1D, they rely on detailed 2D calculations, so they also seem numerically reliable. The main missing validation would be to confirm the actual limit capacity of VCHPs regarding thermal power transport. This validation is out of the scope of the present work, but previous work by the authors [12] and established bibliography [20] seem to support the validity of using VCHPs and VCTSs for similar purposes. Moreover, the entrainment limit of typical heat pipes might be overcome through flooded operation and by carefully designing a return line providing some loop operation.

\section{RESULTS}

Simulations were performed for a system with 64 TEGs according to the scheme of Figure 2, installed in a generic light duty vehicle with a mass of $1400 \mathrm{~kg}$, a drag coefficient of 0.27 and a naturally aspirated $1.6 \mathrm{~L} 118 \mathrm{hp}$ gasoline engine, as already detailed in [28]. The simulations were performed for two distinct driving cycles, a custom HighWay (HW) cycle and the standard WLTC Class 3 cycle and for two types of commercial TEG modules. These were the GM250-49-45-25 (5.3 mm thickness, 15.2 $\mathrm{W}$ maximum output power) and the GM250-127-28-10 (4 mm thickness, $28.3 \mathrm{~W}$ maximum output power) from Adaptive / European Thermodynamics [24]. These two module references represent two different philosophies: low heat consumption (with low output) and high output (with high heat consumption), respectively. Their maximum efficiency is around $5 \%$ and they are able to withstand tempertures up to $250^{\circ} \mathrm{C}$, which was set as the target operating temperature of the system. The heat spreading is processed at this temperature, meaning that the phase change fluid to be used in the VCHPs could be Dowtherm-A at around 1 bar of pressure or water at around 40 bar of pressure, which would require higher resistance heat pipes. In these simulations, a water flow rate of $150 \mathrm{~L} / \mathrm{h}$ was considered for the coolant flow across each cooling plate. The total pumping power estimated for this circuit was about $27.5 \mathrm{~W}$.

\section{Temperature distribution, heat accumulation and spreading for selected time steps}

As explained above, the function of the VCHPs is to spread the excess heat of the hotter upstream sections to the downstream regions along the HE where there is heat deficit. The net accumulation of heat along the length of the HE is computed based on the sum of the heat excess/deficit computations for the upstream sections (which in reality corresponds to the net accumulation of vapour due to vapour generation/condensation in each section).

To highlight the model's behaviour, sample results are presented for specific low, medium and high exhaust power events occurring along the HW cycle for the case of the GM127 modules. Specifically, these three events correspond to instants $94 \mathrm{~s}, 219 \mathrm{~s}$ and $499 \mathrm{~s}$ of the HW cycle, which correspond to an exhaust power of $6.3 \mathrm{~kW}, 18.2 \mathrm{~kW}$ and $51.4 \mathrm{~kW}$, respectively. Figure $8 \mathrm{a}, \mathrm{b}$ ), and c) presents the longitudinal temperature distribution of the exhaust flow, TEG hot face, TEG cold face and coolant flow for those three different exhaust power events. Figure 8d, e) and f) shows, for the same three cases, the heat absorbed by the HE, the heat absorbed by the VCHPs and the heat accumulated in the VCHPs at each section. The lines displayed in these graphs were already explained before when presenting Figure 5. The lower exhaust power values of the cycle occur when the engine is idling, which is represented in Figure 8a and d). There one can see that, as the available exhaust power is low, it is completely absorbed by the HE. In fact, the hot and cold side temperatures are very close in the second half of the HE, which means that the effectiveness of the HE is almost unity as seen further ahead. Also, as consequence of the low available power, the cooling water temperature practically does not rise, except for a hardly noticeable increase of $6 \mathrm{~K}$ in the first $10 \mathrm{~cm}$ of $\mathrm{HE}$ length. Concerning the thermal powers, no heat absorbed/accumulated by the VCHPs could be detected in Figure $8 \mathrm{~d}$ because the temperature at the hot face did not achieve the $523 \mathrm{~K}$ limit which would activate the phase change in the VCHPs. Under these conditions the TEG modules never achieve their optimal operating temperature $(523 \mathrm{~K})$. 


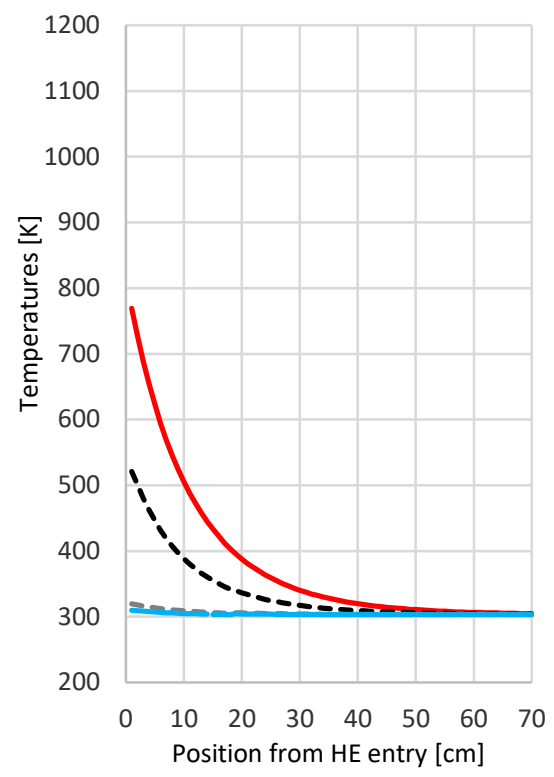

a)

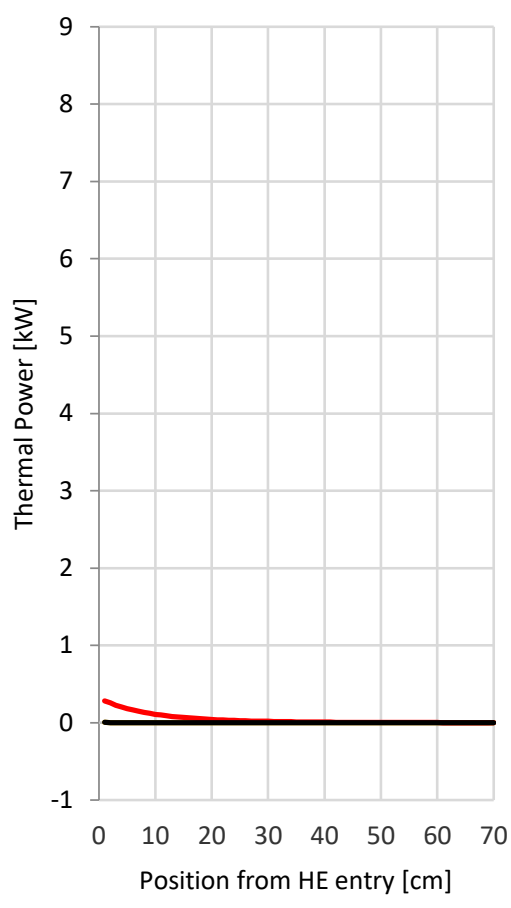

d)

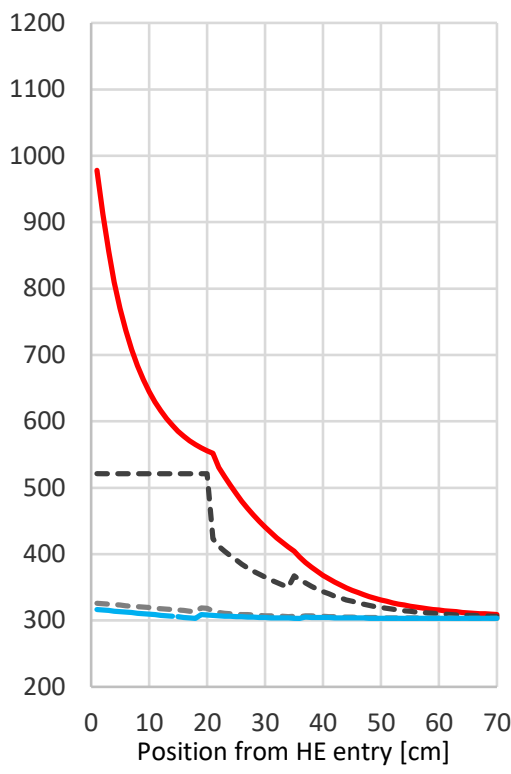

b)

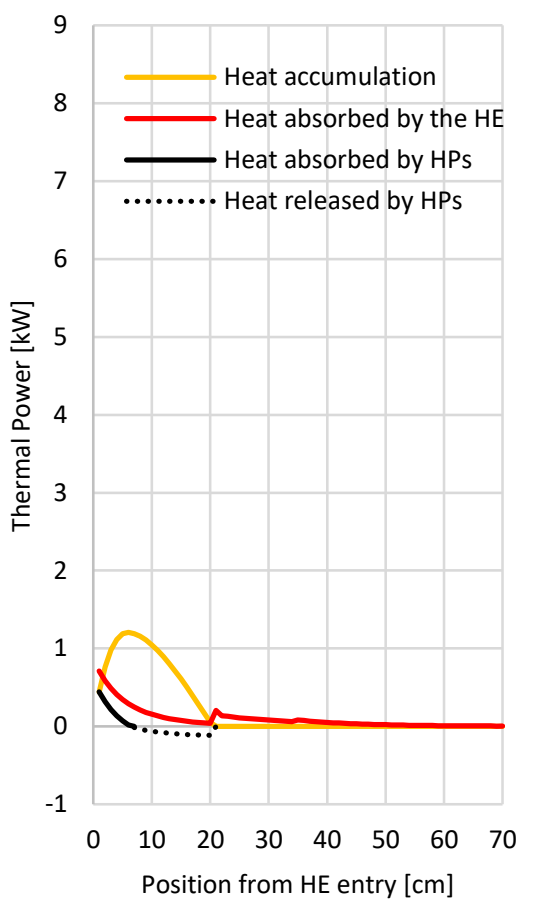

e)

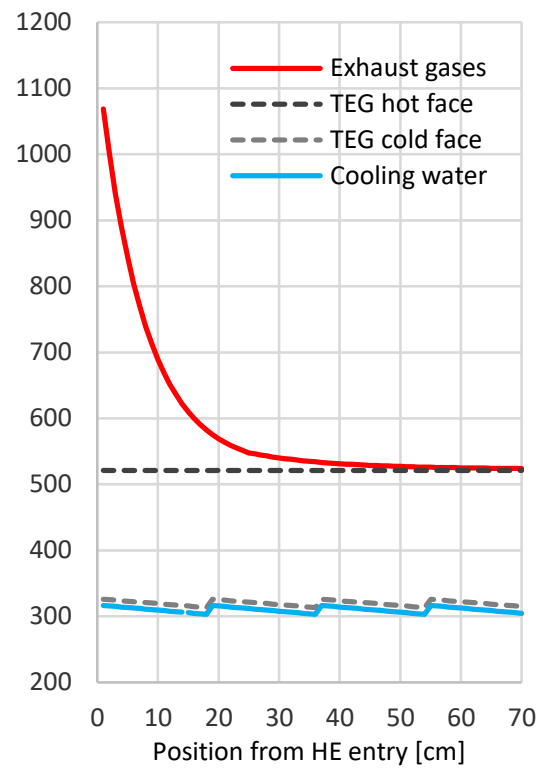

c)

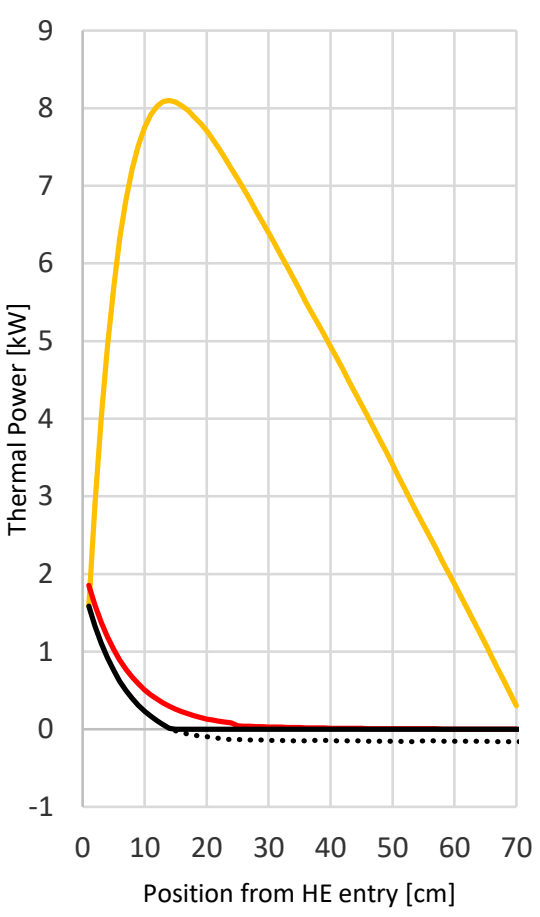

f)

Figure 8 - Temperature profiles and thermal power variation along the HE length for several instants of the HW cycle: a,d) a low exhaust power setting (instant $94 \mathrm{~s}$ ); b, e) an average exhaust power setting (instant $219 \mathrm{~s}$ ); c, f) a high exhaust power setting (instant $499 \mathrm{~s})$.

For the medium thermal power available the temperature variation and thermal power transfer are represented in Figure $8 \mathrm{~b}$ and e), respectively. Under these conditions the HPs are now in operation (working fluid is in phase change) during the first $20 \mathrm{~cm}$ of the HE, where the excess heat accumulated in the first $8 \mathrm{~cm}$ (vapour production) spreads along the following sections (between 8 and $20 \mathrm{~cm}$ ) as depicted in Figure 8e. Since in this last section the heat is being released by HPs, the heat absorbed by HPs in Figure 8e is presented as negative,. Under these conditions, if the HPs were not present, overheating would occur at the excess region (first $8 \mathrm{~cm}$ ) and under-heating would occur along the remainder of the length. The corresponding TEG module temperatures profile can be seen in Figure $8 \mathrm{~b}$ ), there it may be observed that after all the excess heat accumulated has been spread from higher to lower temperature areas, a drop in TEG module hot face temperature occurs for values which are lower than the optimal value. This means that downstream of this point the HP 
is no longer spreading excess heat because all the heat absorbed by the HPs at the excess region has been spent in the deficit region.

Downstream of the regions where the HPs are active, the heat is again transmitted solely by conduction across the HE because the HPs are filled with non-condensable gas in this region. In Figure 8e) an increase can be observed in the amount of the heat absorbed by the HE immediately downstream of the active HP area. What happens is that downstream of this point the HPs become inactive and the gases suddenly stop exchanging heat with a $523 \mathrm{~K}$ heat sink and start exchanging heat with a cooler heat sink which is the cooling water. That increase in heat transfer is proportional to the increase in the temperature difference to the new heat sink.

Figure $8 \mathrm{c}$ shows the temperature variation along the HE for a high power event. In this case the TEG hot face temperature is at its maximum allowable temperature (which is also the optimum temperature) all along the length of the HE. In Figure $8 \mathrm{f}$ it can be seen that there is excess thermal power accumulated in the HPs during the first $14 \mathrm{~cm}$ of the HE. This accumulation is then spreads along the whole remaining length of the HE. Under these conditions a maximum accumulation around $8 \mathrm{~kW}$ was achieved. It is worth noting that in the case of the high power event the exhaust gases exchange heat with a heat sink which is at $523 \mathrm{~K}$ (the HPs) and not at the temperature of the cooling water (around 303 $\mathrm{K})$. That is why the exhaust gases will not drop below $523 \mathrm{~K}$ in this case. For higher exhaust powers, there will be no further improvement of the electrical output, so a by-pass valve may be opened to avoid the need for additional excess power transfer through the HP system. Additionally, the by-pass of excess exhaust flow will also avoid unnecessary losses due to exhaust back-pressure.

\section{Electrical output and efficiency}

It is worth observing the behaviour of the system along the driving cycles. Figure 9 and Figure 10 show the available thermal power at the exhaust and the electrical power output along the HW and WLTC cycles, respectively, for both TEG module references. It may be seen (especially in the HW cycle - Figure 9) that the electrical power presents a maximum value plateau during the high thermal power events despite the variable behaviour of the exhaust power. This corresponds to a situation similar to that presented in Figure 8c,f where the generator is under full operation and the VCHPs prevent the modules from overheating, transferring the heat within the system. Under these conditions, the VCHPs spread the excess heat by phase change and equalize the thermal level of the TEG hot face at $250^{\circ} \mathrm{C}$ along the whole length of the generator despite the variability of the thermal power.

It may be observed that the GM127 modules display a higher maximum power than the GM49 modules. This is because the former modules also produce more power per module for a given temperature difference, although they also need more thermal power to achieve that temperature difference. For each module reference the same maximum electrical output was achieved for both cycles. In the case of the WLTC cycle the maximum electrical output was attained only during its final stages, where high power events occur, (see Figure 10). These maximums are obtained when all modules have their hot face temperature at $250^{\circ} \mathrm{C}$ (similar to what happens in Figure 8c) which in the present case is their maximum allowable temperature.

It is worth noting that the system must incorporate an excess vapour condenser for the case where the thermal spreading exceeds the length of the heat exchanger. This condenser is what effectively prevents the system from increasing its pressure beyond certain limits in the event of excessive exhaust power.

In Figure 9 and Figure 10 it may be seen that during lower regimes the module which consumes less heat for a given temperature difference (GM49) shows a slightly better performance than GM127. This is particularly clear between $600 \mathrm{~s}$ and 700s in the HW cycle, and between $1200 \mathrm{~s}$ and $1350 \mathrm{~s}$ in WLTC cycle, where the GM49 features slightly higher electrical power output than the GM127. This is explained by the TEGs different thicknesses and thermal resistances. Since the thermal resistance of GM49 is higher than GM127, under the same heat sink and heat source temperatures there will be a lower thermal power transfer. This will cause lower temperature losses across each thermal resistance, causing a smaller deprecation of the temperature differential $(\Delta \mathrm{T})$ across the thermoelectric elements, which is directly responsible for the voltage generation. 


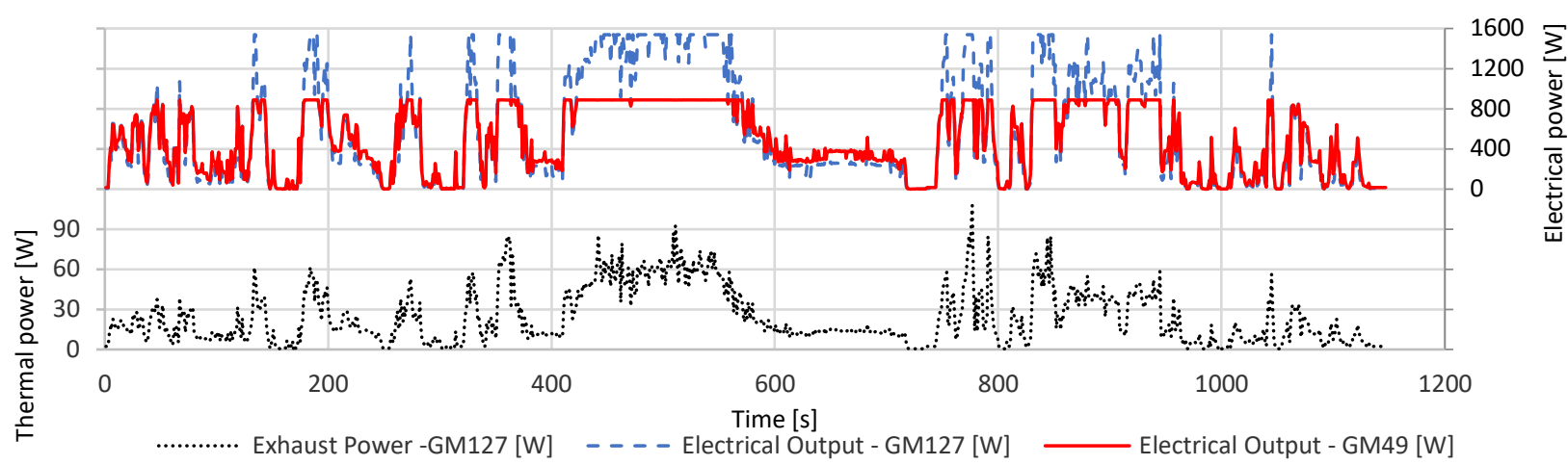

Figure 9 - Thermal input and electric power output along the custom HW driving cycle.

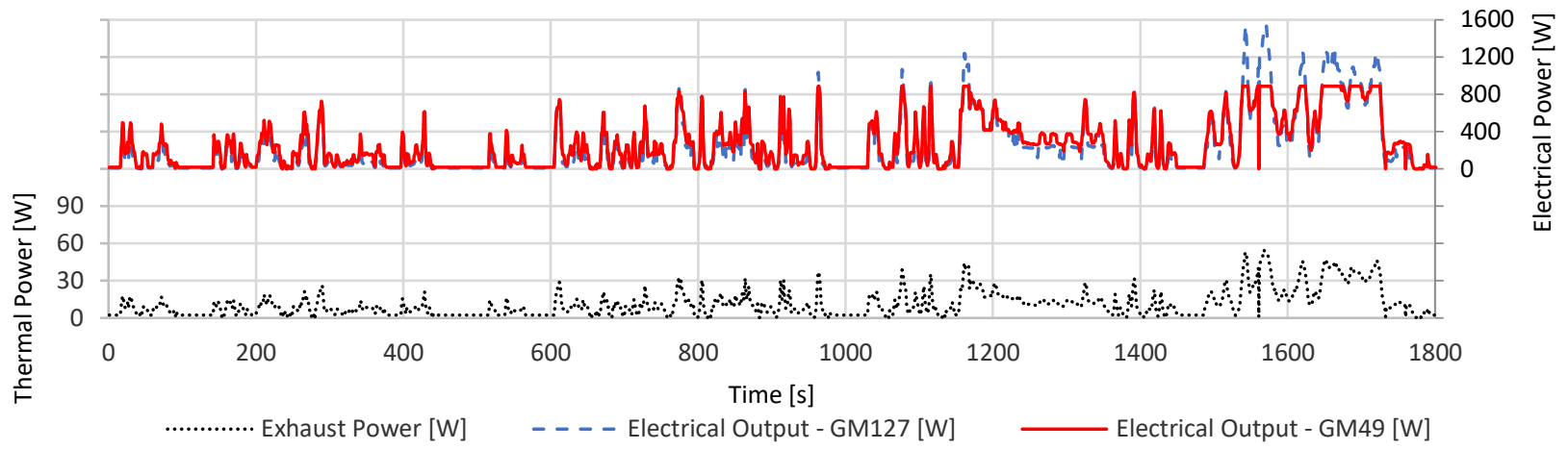

Figure 10 - Thermal input and electric power output along the WLTC driving cycle

The net effect of the electricity production along the different cycles can be seen in Figure 11 which displays the average and maximum powers achieved with both module references for the WLTC and HW cycles. In terms of average output power, as shown in Figure 11, higher values were achieved by the heavier duty HW cycle compared to the WLTC cycle because of the much higher available exhaust thermal power. It is worth noting that for a given module reference the maximum output is similar for both cycles since both achieved the maximum output of the system, which is when the incoming heat is sufficient for the heat spreading extending to the whole length of the generator. This provokes a uniform hot face temperature in all modules close to the boiling temperature of the VCHPs. In the present work this temperature is around $250^{\circ} \mathrm{C}$ (the limit of the modules used). It is also worth noting that the power-oriented modules (GM127) yield a higher average power than the efficiency-oriented modules (GM49) in the heavy duty HW cycle (572W vs $483 \mathrm{~W}$ ), they produce slightly less than the latter ones in the WLTC cycle which has a lower average power (226W vs $256 \mathrm{~W})$. This is because efficiency starts to be a determining factor once the available exhaust power is lower.

It is important to compare these results against the state-of-the-art results from literature. Shen et al [43] provide a useful revision. The most performant automotive TEGs reported achieve around $1 \mathrm{~kW}$, but they are applied to heavy duty vehicles [44]-[46]. Crane et al [47] also developed a valuable prototype in conjunction with industry which yielded more than $600 \mathrm{~W}$ using a BMW X6 SUV. While comparisons between a simplified model such as the present one and actual experimental values might not be totally conclusive, it is worth mentioning other theoretical analyses such as that by GM applied to a Chevrolet Suburban SUV predicting a maximum output of 550W [48] or the study by Vale et al [49] which predicted 188W/886W for a lightweight/heavyweight vehicle. Regarding average output for lightweight vehicles there seems really to exist no comparable results in literature, so the performance of the present concept seems rather promising. 


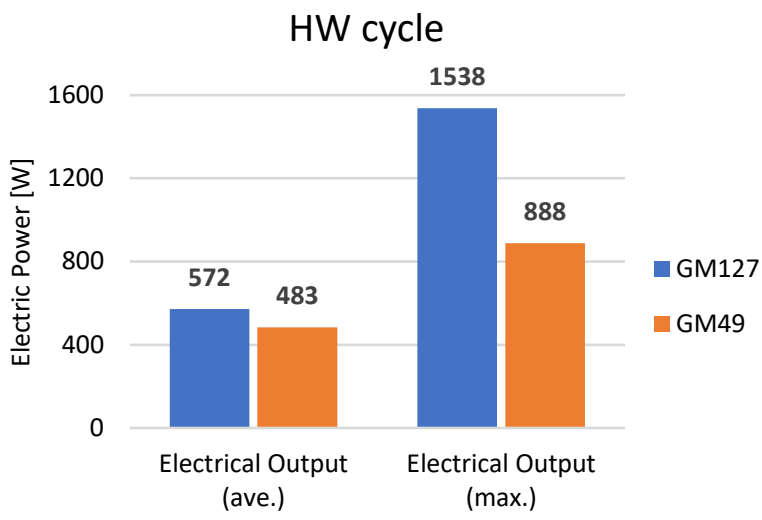

a)

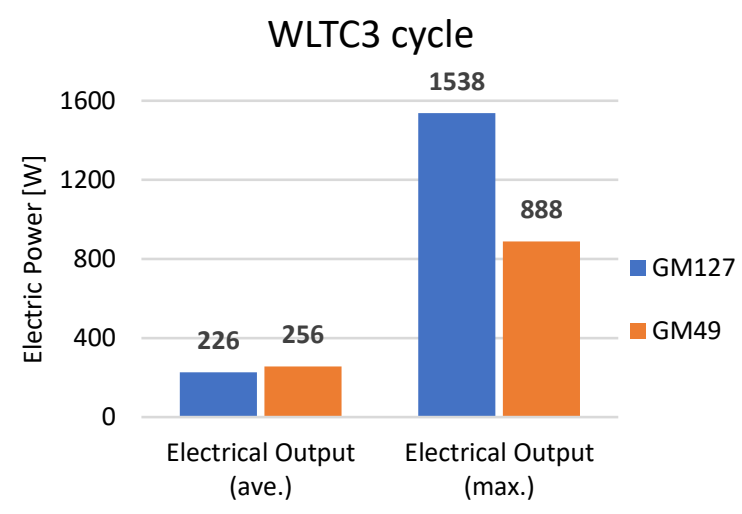

b)

Figure 11 - Average and maximum electric power obtained from: a) highway cycle and b) WLTC3 cycle.

The conversion efficiencies of the TCTG were also assessed for the highway driving cycle. It should be noted that the maximum efficiency of the modules chosen is below $5 \%$ for the temperature differences at stake. So, in order to assess the merit of the thermal control strategy it is more important to assess the efficiency relatively to the theoretical maximum, rather than in absolute terms. Two different conversion efficiencies are represented in the figures below: One efficiency is calculated as a function of the heat crossing the TEG modules (Figure 12). This represents the thermal to electrical conversion efficiency based on the amount of thermal power that traverses the TEG modules. Another efficiency is calculated as a function of the total power available in the exhaust gases (Figure 13), which shows the net conversion efficiency in relation to all the heat available in the exhaust. In these graphics each dot represents one time step of the HW cycle, with all the parameters being presented as a function of the power available in the exhaust gases for that time step. The output power is also represented in these graphs.

The several steps found in the scatter plot correspond to the several TEG module rows, which are activated sequentially by the HP system as the available exhaust power increases.

It is visible in Figure 12 that for the case of the thicker modules (GM49) the electric power output and the conversion efficiency (as a function of the power traversing the TEG) increase with the available exhaust power up to $888 \mathrm{~W} / 4 \%$, respectively, until around $34 \mathrm{~kW}$ of available power. For higher available powers the power and efficiency remain constant.

For the case of the thinner modules (GM127) their power continues to rise past the $34 \mathrm{~kW}$ limit until $53 \mathrm{~kW}$. Above this exhaust power the power and the efficiency stabilize at $1538 \mathrm{~W}$ and $3.8 \%$, respectively. Above these exhaust power levels ( $34 \mathrm{~kW}$ for GM49 and 53kW for GM127) it can be seen that both the electric power and the conversion efficiency no longer increase but remain constant. This means that for higher values of exhaust power there is enough available power to activate the entire length of the HP. Under such conditions, all the modules will be active and at an optimum hot side temperature $\left(\sim 250^{\circ} \mathrm{C}\right)$, with the HPs absorbing all excess heat and spreading it along the system length.

On the other hand, it may be seen in Figure 13 that the overall system conversion efficiency starts to decrease under excess power conditions because the system cannot convert more heat into electricity than a certain maximum amount. All excess heat will be rejected, so the overall conversion efficiency will naturally decrease if more heat is supplied than the system can absorb. To increase the electric output even further, a higher amount of TEG modules would have to be used, increasing the maximum power but also the system cost. The possibility of increasing the system power in a easy way is one of the main advantages of thermoelectric generators: their modularity and scalability.

Related to the differences between TEG modules, as mentioned before, the different TEG modules display different thicknesses, different configurations (element size and number) and different thermal resistances (1.1 K/W for GM49 versus $0.6 \mathrm{~K} / \mathrm{W}$ for GM127). Higher TEG module thermal resistance should lead to lower heat flux across the module which will correspond to lower temperature drops across each thermal resistance along the heat pathway, therefore a higher temperature difference across the thermoelectric pellets should exist for the same heat sink and heat source temperatures. The thicker modules (GM49) need less heat to produce their maximum power output, while the thinner ones (GM127) need more thermal power but have a higher electrical output potential. It would be expected that thicker modules would have better efficiencies than thinner ones but according to the datasheets, both have similar conversion efficiencies (around $5 \%$ for a $220^{\circ} \mathrm{C}$ temperature difference when accounting for the reported heat flow through the module) [24].

It may be seen in Figure 12 that the thicker TEGs produce slightly more power than thinner ones in conditions where the exhaust power output is lower. However, as the available thermal power increases, the thinner TEGs tend to surpass the thicker ones. The better performance of the thicker TEG (higher thermal resistance) for lower available thermal power translates into a better power output for the WLTC cycle with an average of $256 \mathrm{~W}$ versus the $226 \mathrm{~W}$ for the thinner 
modules (recall Figure 11). The opposite happens for the HW cycle with higher average available thermal power, where the thinner modules produce on average $572 \mathrm{~W}$ and the thicker ones produce $483 \mathrm{~W}$ (recall Figure 11).

As already mentioned, for the same temperature difference on the TEG module faces they have both the same conversion efficiency, which is close to the module maximum for high thermal powers. For the same available exhaust power, the thicker TEG has a better conversion efficiency in this system, because, since it has a higher thermal resistance, for the same thermal power a higher temperature difference at the TEG module faces will exist. This is observed for the HW cycle in Figure 12 which shows the conversion efficiency based on the amount of thermal power that traverses the TEG modules, that is, the average module efficiency for a given available exhaust power.

Figure 13 shows the conversion efficiency in relation to all the heat available in the exhaust. That is why the values are lower than those on Figure 12, because the system never absorbs all the exhaust heat.

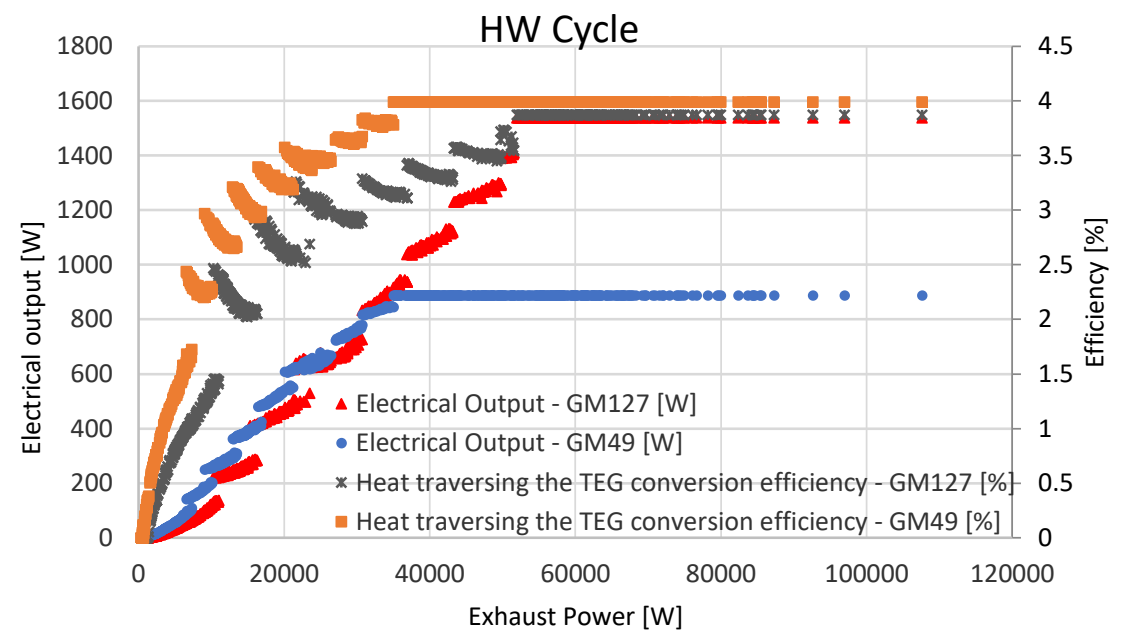

Figure 12 - TEG conversion efficiency as a function of the heat traversing the TEG module, for two types of TEGs

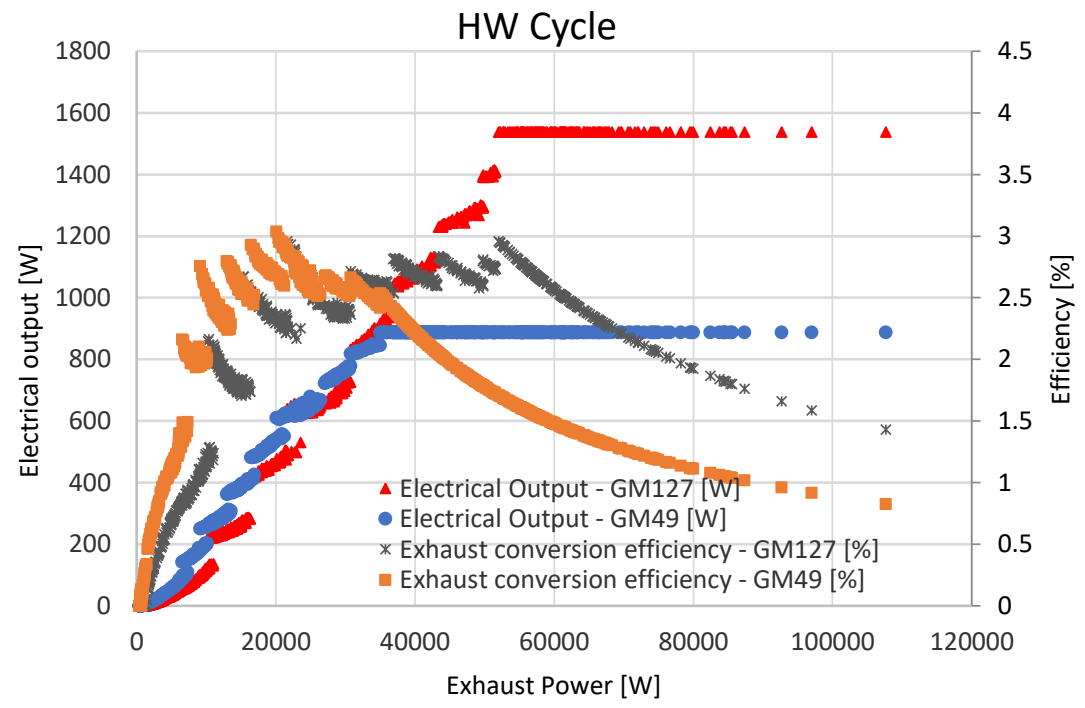

Figure 13 - Overall conversion efficiency as a function of the available exhaust power, for two types of TEGs.

Figure 14 displays the HE effectiveness distribution for the two different TEG modules used (GM127 and GM49) as a function of the exhaust power and also the accumulated occurrences thereof, and for the two driving cycles tested. The effectiveness of a HE is defined as the ratio between the heat transferred between the heat source and heat sink and the maximum transferrable heat between those two. An effectiveness of $100 \%$ means that the exhaust outlet temperature is equal to the inlet coolant temperature so that the heat extracted from the exhaust has reached its theoretical maximum. It can be seen that the $90 \%$ of WLTC3 points have less than $25 \mathrm{~kW}$ of exhaust power, while in the case of the HW cycle, $90 \%$ of the the points are up to $60 \mathrm{~kW}$. 
The HE effectiveness varies considerably as a function of the available exhaust power. When the available thermal power is low the effectiveness of the HE is almost unity, the HE heat transfer area is more than suitable to absorb most of the exhaust heat. The HE effectiveness decreases as the exhaust thermal power increases because the thermal resistances hamper the absorption of the exhaust power. This is particularly the case with thicker TEGs (GM49) because their thermal resistance is higher than that of the thinner TEGs (GM127). Beyond the point where the available exhaust power is such as to activate the entire length of the HP the effectiveness stabilizes. That is so because now the entire length of the HE is losing heat to the HP and not directly to the cooling water. Therefore, the outlet temperature of the exhaust cannot be lower than $523.15 \mathrm{~K}$, limiting the heat transfer potential.

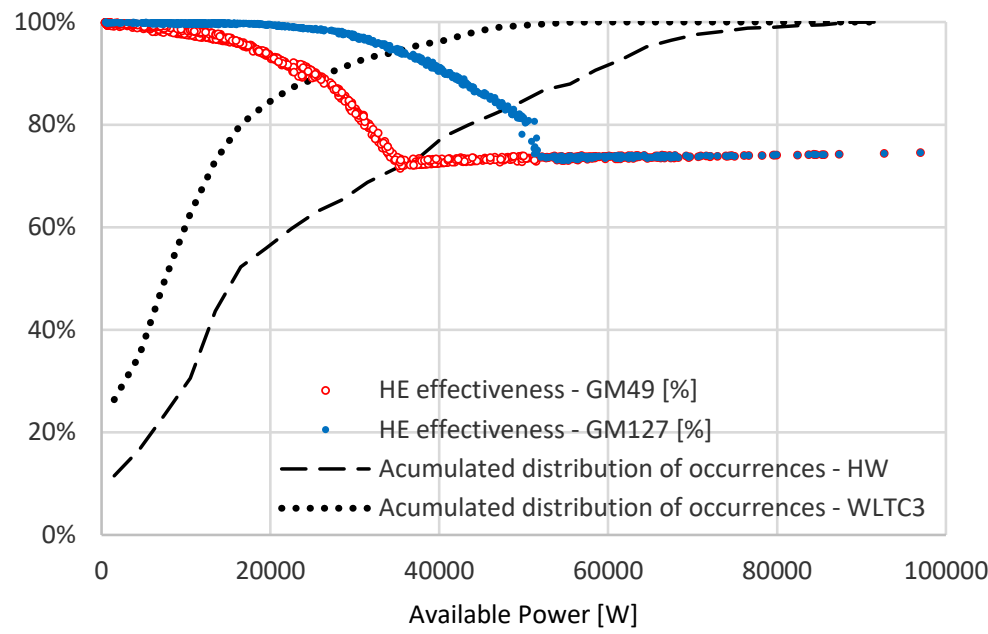

Figure 14 - Heat Exchanger effectiveness and the accumulation of occurrences as a function of the exhaust power

\section{Fuel and $\mathrm{CO}_{2}$ savings}

As shown above, the average electrical power produced seems quite remarkable for light duty vehicles. Although in the WLTC3 cycle the thinner modules (GM127) showed slightly lower performance when compared to thicker ones (GM49), the output of the GM127 is substantially higher than that from GM49 modules for the case with a higher available exhaust power (the HW cycle).

Using the results obtained for the GM127, the fuel consumption and $\mathrm{CO}_{2}$ emission savings were calculated for different cases. Once additional back-pressure in the exhaust pipe affects the engine efficiency [50], in these calculations, the engine power loss due to the back-pressure imposed by the exhaust heat exchanger was also considered. In order to reduce this effect, a bypass valve is considered to exist upstream of the heat exchanger. This valve should start to open once the thermoelectric generator achieves its full power. Since under these conditions the heat exchanger cannot absorb more heat, the remaining exhaust gases may follow an alternative way to avoid additional back-pressure. Figure 15 displays the electric output of the system, the pressure drop and the mechanical power loss associated with it as a function of the exhaust power. It may be seen that if no by-pass valve is used, the pressure drop increases exponentially. However, if a by-pass valve is configured to start opening once the generator is at full operation, then a maximum of $2.5 \mathrm{kPa}$ of pressure drop will be achieved. This corresponds to maximum of around $350 \mathrm{~W}$ of mechanical power losses due to the added exhaust pumping losses. This will reduce the fuel savings obtained with the TEG implementation. 


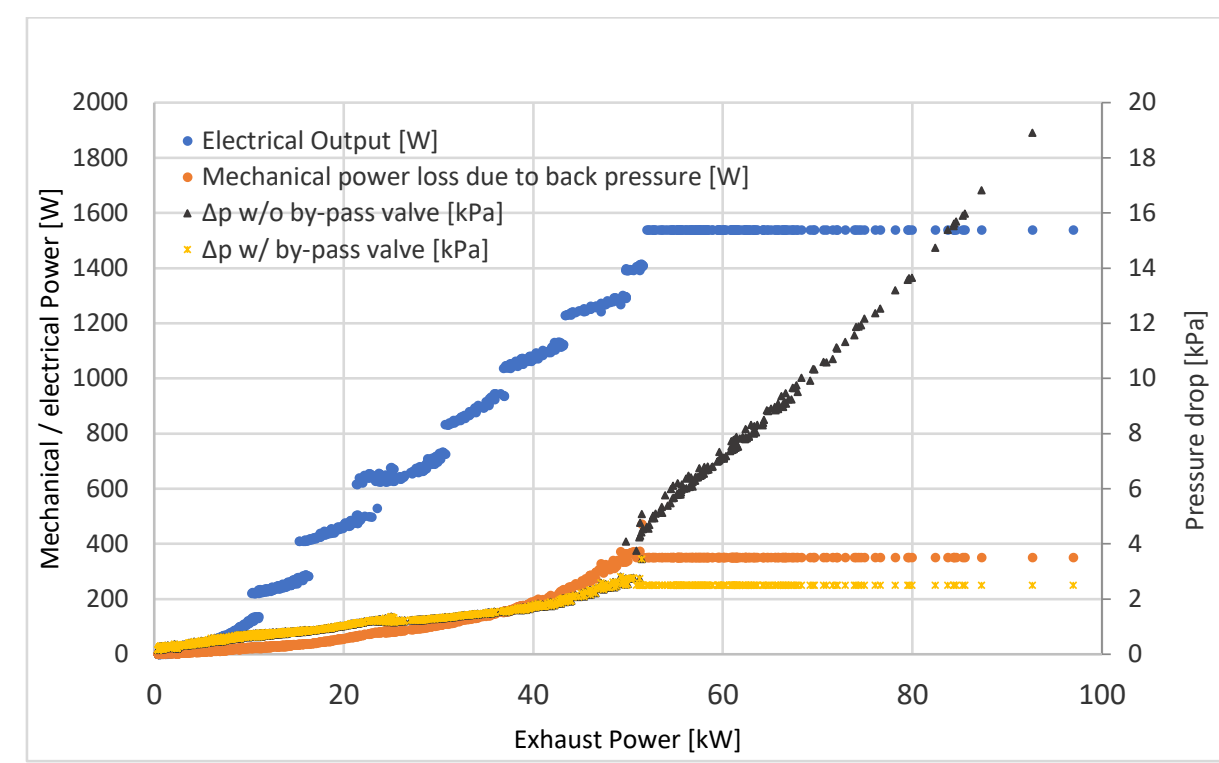

Figure 15 - Pressure drop and engine power loss due to back pressure (HW cycle).

Table 2 shows the driving cycle characterization as well as the potential savings using the present concept to produce the required power, for both HW and WLTC3 cycles. As it may be seen from the table, an average power of $0.27 \mathrm{~kW}$ was obtained for the WLTC3 cycle, and $0.63 \mathrm{~kW}$ for the HW cycle. According to some authors [51], [52] a typical alternator of a light duty vehicle needs to produce an average of $0.5 \mathrm{~kW}$ with an efficiency of $50 \%$, which represents $1 \mathrm{~kW}$ in terms of mechanical power and more than $3 \mathrm{~kW}$ in terms of fuel power. Thus, in the case of $\mathrm{HW}$ cycle, the average power obtained would be sufficient to cover the alternator consumption. This represents a fuel saving of 5.4\% which corresponds to the same percentage in reduction of $\mathrm{CO}_{2}$ emissions.

Regarding the WLTC 3 cycle, the $0.27 \mathrm{~kW}$ produced falls short of the required $0.5 \mathrm{~kW}$ electrical needs, Still, this represents a fuel saving of $4.2 \%$ which is nearly as high as the one obtained for the HW cycle. The main reason for this is that the engine during WLTC3 cycle has a much lower average efficiency, so any savings in the mechanical power requirements will correspond to proportionally higher fuel savings when compared with the HW cycle. Interestingly enough, it may be observed that both cycles produce similar energy per unit distance travelled, except the energy is produced at a faster rate in the HW relatively to the WLTC cycle.

Table 2 - Savings from using TCTG (Using TEGs GM250-127-28-10).

\begin{tabular}{|r|c|c|}
\hline \multicolumn{1}{|l|}{ Driving cycle data: } & HW & WLTC 3 \\
\hline Distance $[\mathrm{km}]$ & 27.1 & 23.3 \\
\hline Average engine efficiency [\%] & $25.3 \%$ & $17.7 \%$ \\
\hline Using TCTG: & 18.7 & 8.58 \\
\hline Everage required Mechanical Power [kW] & & \\
\hline Electric power produced $($ ave. $)[\mathrm{W}]$ & 627 & 267 \\
\hline Energy produced $[\mathrm{kJ} / \mathrm{km}]$ & 26.6 & 20.7 \\
\hline Average required Mechanical Power $[\mathrm{kW}]$ & 17.7 & 7.00 \\
\hline Fuel savings [L/100km /\%] & $0.50 / 5.4 \%$ & $0.47 / 4.2 \%$ \\
\hline $\mathrm{CO}_{2}$ emissions savings [g/km] & 11.99 & 11.14 \\
\hline
\end{tabular}

Now, it is possible to assess the fuel and emissions savings not only for the case where the TCTG would be used for reducing the use of the alternator but it is also possible to evaluate what would be the maximum savings potential if the alternator would be eliminated altogether and several of the mechanical peripherals (AC compressor, fuel pump, water pump) would be substituted by electrically-driven ones. In the case where all the electricity needed to power these peripherals would come from waste energy recovery systems such as TEGs and regenerative braking, the savings could be very substantial. This is especially true in the case of the WLTC3 cycle, where the relative weight of the peripherals in the total required mechanical power of the engine can be very high, as may be seen on Table 3 . 
Table 3 - Calculated yearly fuel and $\mathrm{CO}_{2}$ emissions savings for several user profiles (Using TEGs GM250-127-28-10).

\begin{tabular}{|l|c|c|c|c|}
\hline & \multicolumn{2}{|c|}{ Using TCTG } & \multicolumn{2}{c|}{ Use electric peripherals + energy recovery } \\
\hline \multicolumn{1}{|c|}{$\mathrm{km} /$ year } & $\mathrm{HW}^{*}$ & WLTC $3 *$ & $\mathrm{HW}^{*}$ & WLTC $3^{*}$ \\
\hline $15,000 \mathrm{~km}$ min. EU (UK) $* *$ & $75.2 /(0.19)$ & $69.9 /(0.17)$ & $146.4 /(0.35)$ & $385.0 /(0.92)$ \\
\hline $30,000 \mathrm{~km}$ max. EU (Poland) $* *$ & $150.3 /(0.36)$ & $139.7 /(0.33)$ & $292.9 /(0.70)$ & $770.0 /(1.84)$ \\
\hline $60,000 \mathrm{~km}$ intensive use & $300.7 /(0.72)$ & $279.5 /(0.67)$ & $585.7 /(1.40)$ & $1540.1 /(3.68)$ \\
\hline $120,000 \mathrm{~km}$ extra intensive use & $601.4 /(1.44)$ & $558.9 /(1.34)$ & $1171.5 /(2.80)$ & $3080.3 /(7.37)$ \\
\hline$*$ L gasoline/ (ton $\left.\mathrm{CO}_{2}\right) * *[53]$
\end{tabular}

Table 3 compares the yearly fuel savings computed by the model for different user profiles in two different situations: by only using the TCTG to reduce alternator use and by replacing the alternator and peripherals by electrically driven ones and then admitting that sufficient electrical energy is produced on-board from waste energy recovery sources to supply these systems. Here it can be seen that the fuel and $\mathrm{CO}_{2}$ emissions savings during WLTC3 cycle are quite high in the case of the replacement of both the alternator and peripherals. Table 3 also shows several typical European user profiles with low average vehicle usage $(15,000 \mathrm{~km} / \mathrm{year}$, typical of UK drivers [53]), high average vehicle usage $(30,000 \mathrm{~km} / \mathrm{year}$ typical of Polish drivers [53]), intensive usage (60,000 km/year) and extra-intensive usage (120,000 km/year).

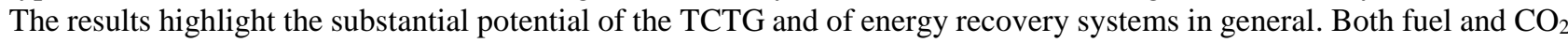
emissions savings are very interesting, from $69.9 \mathrm{~L}$ for an annual use of 15,000 km in WLTC3 cycle to $601.4 \mathrm{~L}$ for the extra-intensive use of $120,000 \mathrm{~km}$ on the $\mathrm{HW}$ cycle, which represents $\mathrm{CO}_{2}$ emissions savings from 0.17 to 1.44 ton, respectively. At the limit, if all peripheral components could be removed and electrically-driven ones would substitute them, maximum potential fuel savings up to $3080 \mathrm{~L} /$ year could be reached, which corresponds to 7.37 ton/year of $\mathrm{CO}_{2}$ emission savings.

\section{CONCLUSION}

The present work analysed the potential of a novel Temperature Controlled Thermoelectric Generator (TCTG) concept applied to a light vehicle, which has been recently submitted for patenting. It consists of corrugated tubes for the exhaust flow and Variable Conductance Heat Pipes (VCHPs), both embedded in a cast aluminium matrix. The VCHPs, which are located across the heat path between the exhaust heat exchanger (HE) and the thermoelectric modules, will start absorbing excess heat by vaporization and spreading it in the longitudinal direction once the maximum allowable temperature is achieved. This heat will then be released to the cooler downstream regions equalizing the hot face temperature where the vapour reaches thus preventing overheating. This concept seems especially suitable for highly variable thermal loads such as those achieved during driving, downgrading the temperature peaks down to an optimized level. It is also compact and suitable for use in vehicles.

A mathematical model was developed to assess the performance of the generator and the corresponding fuel and $\mathrm{CO}_{2}$ emissions savings during driving cycles. A geometrical optimization and a partial validation using CFD simulations was performed. The following results were obtained:

- Average electric powers of 572 W/483 W were predicted for a custom Highway (HW) cycle for TEGs GM127/GM49, respectively. For the WLTC3 cycle 226/256 W were achieved for TEGs GM127/GM49, respectively; the maximum electrical power was similar for both cycles (1538/888 W for TEGs GM127/GM49); These figures seem to be highly promising for TEG systems in such small vehicles and are unparalleled in literature.

- It was found that the TCTG may induce savings of $5.4 \% / 4.2 \%$ in fuel and $\mathrm{CO}_{2}$ emissions when performing the HW/WLTC3 driving cycles, respectively. The estimated annual fuel and $\mathrm{CO}_{2}$ emissions savings were computed for several user profiles, with savings up to $601.4 \mathrm{~L} /$ year of gasoline and 1.44 ton/year of $\mathrm{CO}_{2}$ emissions by implementing the TCTG on a light duty vehicle.

The preliminary assessment of the systems seems to indicate that it has a very good potential for vehicle waste energy recovery applications, particularly for intensive vehicle use where the fuel economy and in $\mathrm{CO}_{2}$ emissions savings are maximized. The main reasons for this are the ability of the concept to maintain the TEG modules close to their optimal hot side temperature while avoiding overheating, spreading excess heat instead of wasting it through by-pass systems. In terms of thermal design, the use of high performance corrugated pipes already used in exhaust applications is clearly an advantage. Currently, casting tests of the concept have already begun. Future work will include extensive numerical and experimental testing in order to fully evaluate this concept for heavy duty applications, where the concept will be most useful. 


\section{ACKNOWLEDGMENTS}

This work has been supported by FCT - Fundação para a Ciência e Tecnologia within the R\&D Units Project Scope: UIDP/04077/2020 within MEtRICs - Mechanical Engineering and Resource Sustainability Centre, Project Exhaust2Energy (PTDC/EMS-ENE/3009/2014) and M-ERA.net Project THERMOSS (M-ERA.net2_0011_2016), financed by European Regional Development Fund (ERDF) funds through P.O.F.C. - COMPETE and National funds through PIDDAC and FCT. The authors also wish to thank Dr. Helder Puga from the Casting Lab of the Mechanical Engineering Department of University of Minho, Paulo Moutinho and BorgWarner Emissions Systems (Spain Technical Center - Vigo, Spain).

\section{REFERENCES}

[1] D. F. Dominković, I. Bačeković, A. S. Pedersen, and G. Krajačić, "The future of transportation in sustainable energy systems: Opportunities and barriers in a clean energy transition,” Renew. Sustain. Energy Rev., vol. 82, pp. 1823-1838, Feb. 2018.

[2] European Parliament and Council of the European Union, "Regulation (EC) no. 443/2009," Off. J. Eur. Union, vol. 140, no. 1, pp. 1-15, 2009.

[3] E. Massaguer, A. Massaguer, T. Pujol, M. Comamala, L. Montoro, and J. R. Gonzalez, "Fuel economy analysis under a WLTP cycle on a mid-size vehicle equipped with a thermoelectric energy recovery system," Energy, vol. 179, pp. 306-314, Jul. 2019.

[4] J. LaGrandeur, D. Crane, S. Hung, B. Mazar, and A. Eder, "Automotive Waste Heat Conversion to Electric Power using Skutterudite, TAGS, PbTe and BiTe," in 2006 25th International Conference on Thermoelectrics, 2006, pp. 343-348.

[5] H. Zervos, "Waste heat recovery systems in vehicles," Energy Harvesting Journal, 2011. .

[6] G. P. Meisner, "Skutterudite Thermoelectric Generator For Automotive Waste Heat Recovery," 3rd Thermoelectric Applications Workshop, 2012. .

[7] M. Mori, T. Yamagami, M. Sorazawa, T. Miyabe, S. Takahashi, and T. Haraguchi, "Simulation of Fuel Economy Effectiveness of Exhaust Heat Recovery System Using Thermoelectric Generator in a Series Hybrid," SAE Int. J. Mater. Manuf., vol. 4, no. 1, pp. 1268-1276, 2011.

[8] S. M. Pourkiaei et al., "Thermoelectric cooler and thermoelectric generator devices: A review of present and potential applications, modeling and materials," Energy, vol. 186, p. 115849, Nov. 2019.

[9] D. M. Rowe, CRC Handbook of Thermoelectrics. 1995.

[10] D. Crane et al., "TEG On-Vehicle Performance \& Model Validation," 2012.

[11] F. P. Brito, J. Martins, L. M. Goncalves, and R. Sousa, "Temperature Controlled Exhaust Heat Thermoelectric Generation," SAE Int. J. Passeng. Cars - Electron. Electr. Syst., vol. 5, no. 2, 2012.

[12] F. P. Brito, J. Martins, E. Hançer, N. Antunes, and L. M. Gonçalves, "Thermoelectric Exhaust Heat Recovery with Heat Pipe-Based Thermal Control,” J. Electron. Mater., vol. 44, no. 6, pp. 1984-1997, 2015.

[13] F. P. Brito et al., "Analysis of a Temperature-Controlled Exhaust Thermoelectric Generator During a Driving Cycle," $J$. Electron. Mater., vol. 45, no. 3, pp. 1846-1870, 2016.

[14] F. P. Brito, L. M. Goncalves, J. Martins, N. Antunes, and D. Sousa, "Influence of heat pipe operating temperature on exhaust heat thermoelectric generation," SAE Int. J. Passeng. Cars - Mech. Syst., vol. 6, no. 2, 2013.

[15] F. P. Brito et al., "Efficiency improvement of vehicles using temperature controlled exhaust thermoelectric generators," Energy Convers. Manag., vol. 203, p. 112255, Jan. 2020.

[16] F. P. Brito, J. Martins, L. M. Goncalves, J. Teixeira, N. Pacheco, and R. Vieira, "System for efficient heat recovery and method thereof," US Patent application, Attorney Docket number 10224/008071/US0, submitted August 8th 2019, originally filed in Portugal in August 8th. 2018 (application number 111106), 2019.

[17] F. P. Brito, J. Martins, L. M. Goncalves, J. Teixeira, N. Pacheco, and R. Vieira, "System for efficient heat recovery," EU Patent application, application number EP19190903.5, submitted August 8th 2019 to European Patent Office, originally filed in Portugal in August 8th, 2018 (application number 111106), 2019.

[18] J. Danielewicz, M. A. Sayegh, B. Śniechowska, M. Szulgowska-Zgrzywa, and H. Jouhara, "Experimental and analytical performance investigation of air to air two phase closed thermosyphon based heat exchangers," Energy, vol. 77, pp. 82-87, Dec. 2014.

[19] H. Jouhara, A. Chauhan, T. Nannou, S. Almahmoud, B. Delpech, and L. C. Wrobel, "Heat pipe based systems - Advances and applications," Energy, vol. 128, pp. 729-754, Jun. 2017.

[20] A. Faghri, Heat Pipe Science and Technology, Second Edi. Global Digital Press, 2016.

[21] H. Shabgard, M. J. Allen, N. Sharifi, S. P. Benn, A. Faghri, and T. L. Bergman, "Heat pipe heat exchangers and heat sinks: Opportunities, challenges, applications, analysis, and state of the art," Int. J. Heat Mass Transf., vol. 89, pp. 138-158, Oct. 2015.

[22] A. L. London, A. D. Kraus, R. K. Shah, and D. E. Metzger, Compact Heat Exchangers: A Festschrift for A.L. London. Hemisphere Publishing Corporation, 1990.

[23] A. E. Risseh, H.-P. Nee, and C. Goupil, "Electrical Power Conditioning System for Thermoelectric Waste Heat Recovery in Commercial Vehicles," IEEE Trans. Transp. Electrif., vol. 4, no. 2, pp. 548-562, Jun. 2018.

[24] European Thermodynamics, "Thermoelectric Generator Modules," 2019. [Online]. Available: https://www.europeanthermodynamics.com/products/thermoelectric-modules/seebeck-generator. [Accessed: 01-Feb-2019].

[25] Y. S. Muzychka and M. M. Yovanovich, "Laminar Forced Convection Heat Transfer in the Combined Entry Region of Non-Circular Ducts,” J. Heat Transfer, vol. 126, no. 1, p. 54, 2004. 
[26] B. Ribeiro and J. Martins, "Direct Comparison of an Engine Working under Otto, Miller and Diesel Cycles: Thermodynamic Analysis and Real Engine Performance," 2007.

[27] B. R. S. Ribeiro, "Thermodynamic optimisation of spark ignition engines under part load conditions, PhD Thesis," Universidade do Minho, 2006.

[28] J. M. Pires, "Modelação de Ciclos Orgânicos de Rankine utilizando o calor do escape de veículos em condições reais de circulação," Universidade do Minho, 2014.

[29] G. P. Blair, Design and Simulation of Four-Stroke Engines. Warrendale, PA (USA): SAE International, 1999.

[30] W. J. D. Annand and T. H. Ma, "Instantaneous Heat Transfer Rates to the Cylinder Head Surface of a Small CompressionIgnition Engine," Proc. Inst. Mech. Eng., vol. 185, pp. 976-987.

[31] D. Sandoval and J. B. Heywood, “An Improved Friction Model for Spark-Ignition Engines,” SAE Trans., vol. 112, pp. 1041-1052, 2003

[32] HEYWOOD and J. B., Internal Combustion Engine Fundamentals. McGraw-Hill, 1988.

[33] L. A. S. B. Martins, J. M. O. Brito, A. M. D. Rocha, and J. J. G. Martins, "Regenerative braking potential and energy simulations fora plug-in hybrid electric vehicle under real driving conditions," in ASME International Mechanical Engineering Congress and Exposition, Proceedings, 2010, vol. 6, pp. 525-532.

[34] L. A. S. B. Martins, B. J. O. Araujo, J. J. G. Martins, and F. C. P. Brito, "Methodology for the Energy Characterization of Type-Approval and Real-World Driving Cycles for Passenger Vehicles," in ASME International Mechanical Engineering Congress and Exposition, Proceedings (IMECE), 2015, vol. 6A-2015, no. November 2015.

[35] Y. Cengel, R. Turner, and J. Cimbala, "Fundamental of thermal fluid sciences." p. 1079, 2008.

[36] A. I. Zografos, W. A. Martin, and J. E. Sunderland, "Equations of properties as a function of temperature for seven fluids," Comput. Methods Appl. Mech. Eng., vol. 61, no. 2, pp. 177-187, 1987.

[37] T. S. Ravigururajan and A. E. Bergles, "Development and verification of general correlations for pressure drop and heat transfer in single-phase turbulent flow in enhanced tubes," Exp. Therm. Fluid Sci., vol. 13, no. 1, pp. 55-70, Jul. 1996.

[38] S. K. Saha, "THERMOHYDRAULICS OF LAMINAR FLOW THROUGH A CIRCULAR TUBE HAVING INTEGRAL HELICAL CORRUGATIONS AND FITTED WITH HELICAL SCREW-TAPE INSERT," Chem. Eng. Commun., vol. 200, no. 3, pp. 418-436, Mar. 2013.

[39] H. K. Versteeg and W. Malalasekera, An introduction to computational fluid dynamics: the finite volume method. Longman Group Ltd, 1995.

[40] J. P. Holman, Heat Transfer, 10th Editi. New York: McGraw Hill Education, 2010.

[41] W. He and S. Wang, "Thermoelectric performance optimization when considering engine power loss caused by back pressure applied to engine exhaust waste heat recovery," Energy, vol. 133, pp. 584-592, 2017.

[42] T. Y. Kim and J. Kim, "Assessment of the energy recovery potential of a thermoelectric generator system for passenger vehicles under various drive cycles," Energy, vol. 143, pp. 363-371, Jan. 2018.

[43] Z. G. Shen, L. L. Tian, and X. Liu, "Automotive exhaust thermoelectric generators: Current status, challenges and future prospects,” Energy Convers. Manag., vol. 195, no. February, pp. 1138-1173, 2019.

[44] J. C. Bass, N. Elsner, and F. Leavitt, "Performance of the $1 \mathrm{~kW}$ thermoelectric generator for diesel engines," AIP Conf. Proc., vol. 316, no. 1, pp. 295-295, 1995.

[45] Y. Zhang et al., "High-temperature and high-power-density nanostructured thermoelectric generator for automotive waste heat recovery," Energy Convers. Manag., vol. 105, 2015.

[46] X. Liu, Y. D. D. Deng, Z. Li, and C. Q. Q. Su, "Performance analysis of a waste heat recovery thermoelectric generation system for automotive application," Energy Convers. Manag., vol. 90, pp. 121-127, Jan. 2015.

[47] D. Crane et al., "TEG On-Vehicle Performance and Model Validation and What It Means for Further TEG Development," J. Electron. Mater., vol. 42, no. 7, pp. 1582-1591, Jul. 2013.

[48] S. Kumar, S. D. Heister, X. Xu, J. R. Salvador, and G. P. Meisner, "Thermoelectric generators for automotive waste heat recovery systems part I: Numerical modeling and baseline model analysis,” J. Electron. Mater., vol. 42, no. 4, pp. 665-674, 2013.

[49] S. Vale, L. Heber, P. J. Coelho, and C. M. Silva, "Parametric study of a thermoelectric generator system for exhaust gas energy recovery in diesel road freight transportation," Energy Convers. Manag., vol. 133, pp. 167-177, Feb. 2017.

[50] T. Y. Kim, J. Kwak, and B. wook Kim, "Application of compact thermoelectric generator to hybrid electric vehicle engine operating under real vehicle operating conditions," Energy Convers. Manag., vol. 201, Dec. 2019.

[51] B. Carlson, "On-road Data Collection and Analysis: 12 Volt Auxiliary Load, Energy Storage \& Transportation Systems," 2015. .

[52] M. Bradfield, "Improving Alternator Efficiency Measurably Reduces Fuel Costs.” 2008.

[53] P. K. Guzay et al., "Driving and parking patterns of European car drivers - a mobility survey," 2012. 